\title{
Force Generation by Microtubule Assembly/Disassembly in Mitosis and Related Movements
}

\author{
Shinya Inoué ${ }^{* \dagger}$ and Edward D. Salmon ${ }^{\ddagger}$ \\ *Marine Biological Laboratory, Woods Hole, Massachusetts 02543; and ${ }^{\ddagger}$ Department of Biology, \\ University of North Carolina, Chapel Hill, North Carolina 27599
}

Submitted June 2, 1995; Accepted August 30, 1995

Monitoring Editor: Thomas D. Pollard

In this article, we review the dynamic nature of the filaments (microtubules) that make up the labile fibers of the mitotic spindle and asters, we discuss the roles that assembly and disassembly of microtubules play in mitosis, and we consider how such assembling and disassembling polymer filaments can generate forces that are utilized by the living cell in mitosis and related movements.

\section{EARLY HISTORY: THE DYNAMIC EQUILIBRIUM MODEL}

The orderly segregation of chromosomes at every cell division, and the placement of the resulting daughter nuclei into appropriate cytoplasmic environments, are essential for the normal development of an organism, the generation of functional tissues and gametes, and indeed for the continuity of life itself. Such bipolar segregation of chromosomes in mitosis, and the movement of centrosomes that position the daughter nuclei into appropriately partitioned regions of the cytoplasm in animal cells are accomplished by a bipolar mitotic spindle and its associated astral rays.

Although the significance of the spindle and astral rays for mitosis and for the coordination of mitosis with cell cleavage were well recognized by the early cytologists, much controversy abounded in the first half of this century regarding the actual nature of the mitotic spindle fibers (Wilson, 1928; Schrader, 1953). Although visible in cells exposed to acidic or proteinprecipitating fixatives, the fibers were not visible by bright field or phase contrast microscopy in most living cells and were absent in cells observed by light or electron microscopy after fixation with what were considered to be better structure-preserving reagents. There were indications that the fibers would disappear reversibly in cells treated with low temperature or with ethyl ether, and that they were so labile that chromosomes having to traverse laterally to accom-

\footnotetext{
${ }^{+}$Corresponding author.
}

plish their anaphase separation could even cut right through the fibers (Östergren, 1949). Yet without the bipolar fibrous organization, what would move or guide the chromosomes to the spindle poles?

The reality in living cells of spindle fibers, and the fibrils that as a bundle made up the fibers, were established by Inoue by observing a variety of living, animal and plant cells in division with a sensitive polarized light microscope (Inoué, 1951-1953, 1964). The birefringence of the fibers measured and photographed through the sensitive polarizing microscope depicted the distribution, concentration, and appearance and disappearance of oriented fibrils in the spindle fibers in living cells. In addition to the dynamic formation, fluctuation, and disappearance of these fibers and fibrils during the normal course of cell division, the birefringence revealed the labile nature of the fibrous spindle elements in cells exposed to cold or to a mitosis-inhibiting alkaloid, colchicine (Inoué, 1952, 1964). From these findings, Inoué postulated that the spindle fibers and fibrils were made up of a loosely coupled, linear chain of protein molecules, which were in a temperature-sensitive dynamic equilibrium with their pool of subunits that make up the chain. The assembly was entropy driven, and the equilibrium toward polymer formation was favored at elevated temperatures and less favored at a lower temperature (Inoué, 1951, 1959).

Furthermore, by making the fibers and fibrils depolymerize slowly by chilling a living cell, exposing them to elevated hydrostatic pressure, or by applying moderate doses of colchicine solutions to metaphase 
cells, Inoue and his coworkers demonstrated that the depolymerizing spindle fibers and fibrils could generate enough force to transport chromosomes and the whole spindles through the cytoplasm to an anchorage site at cell surface (Figure 1). Conversely, the assembly of subunits from the pool into the growing protein fibrils could generate a force that would push chromosomes, and the whole spindle, away from the

A

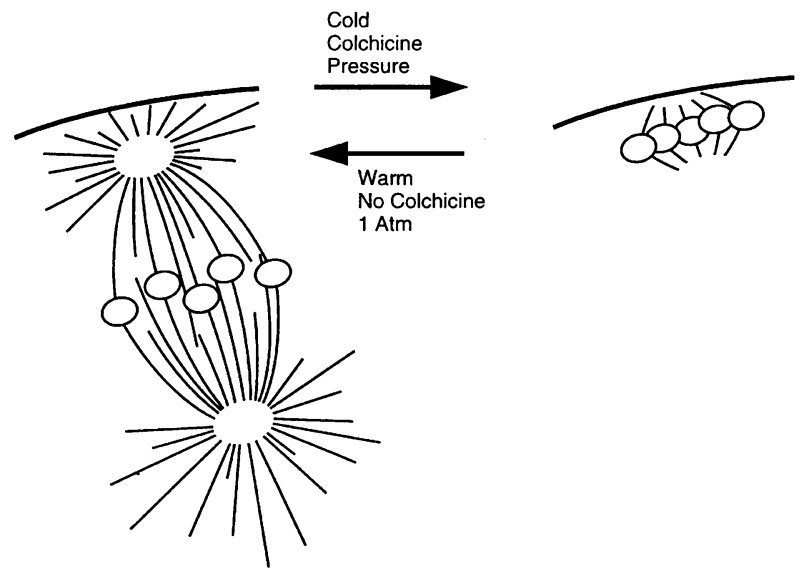

B

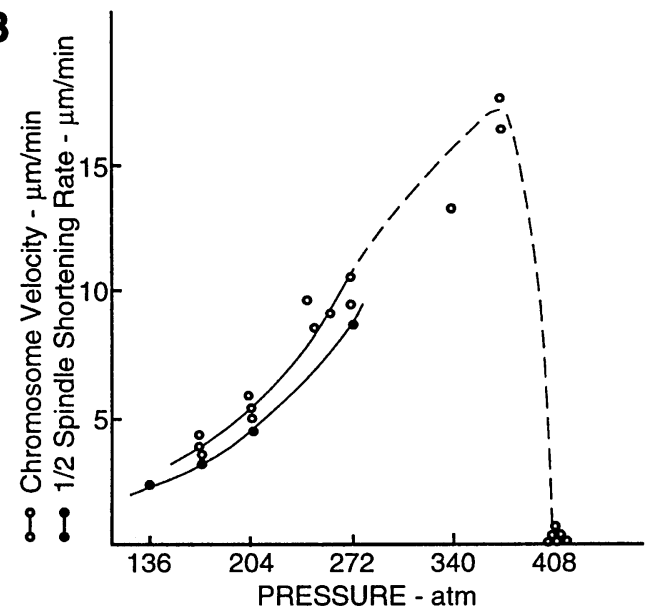

Figure 1. Chromosome movement induced by microtubule assembly/disassembly in meiotic metaphase-arrested Chaetopterous spindles. (A) Movements of chromosomes toward the cell surface induced by shortening of kinetochore fibers and astral rays accompanying loss of birefringence (number of microtubules). Microtubule disassembly is induced reversibly by cooling, or by application of colchicine or hydrostatic pressure. The chromosomes move back away from the attached pole upon spindle reassembly (Inoué, 1952; Inoué et al., 1975; Salmon, 1976). (B) Velocities of chromosomes as they move toward the cell surface during hydrostatic pressure-induced depolymerization of kinetochore microtubules in the metaphase spindle. The greater the hydrostatic pressure applied, the faster the microtubules depolymerize and the faster the chromosomes and the spindle pole are transported toward the anchorage site on the cell surface. Above about 370 atm, microtubule depolymerization was too rapid to generate any pulling force (Salmon, 1976). anchorage site (Inoué, 1952; Inoué and Sato, 1967; Inoué et al., 1975; Salmon et al., 1976).

By the mid 1960's, microtubules, which earlier had not been seen in the spindle region, were clearly visualized by electron microscopy using improved, osmium- and glutaraldehyde-containing fixatives (Harris, 1962; reviewed by Porter, 1966). The distribution and behavior of the microtubules closely paralleled those of the birefringent fibrils that had been described earlier within the spindle fibers. In 1967, Inoué and Sato (1967) were able to explicitly propose that depolymerizing microtubules could perform mechanical work by pulling, and conversely, polymerizing and growing microtubules could exert a pushing force. The former mechanism could draw the chromosomes via their spindle fiber attachment site, the kinetochore, to the spindle pole. The latter could, for example, extend the distance between the two poles of the spindle.

In 1972, Weisenberg (1972) developed a method for isolating microtubules whose properties finally resembled the behavior of the spindle fibrils in living cells. Unlike all earlier methods for isolating microtubules or the spindle apparatuses, which yielded only stabilized structures that were unresponsive to cold or to colchicine, microtubules isolated according to Weisenberg's method yielded microtubules that disassembled into their subunit tubulin dimers upon chilling. Furthermore, they reassembled into their tubular polymer state (the microtubules, Figure $2 \mathrm{~A}$ ) at room temperature in the presence of magnesium ions, GTP, and neutral organic buffer, provided the calcium ion concentration was kept below about $100 \mathrm{nM}$. The reassembled microtubules would depolymerize again when exposed to low temperature or high hydrostatic pressure (Borisy et al., 1975; Olmsted and Borisy, 1975; Salmon, 1975; Weisenberg, 1972). The reassembly was inhibited by colchicine, and accelerated by $\mathrm{D}_{2} 0$ that increases the birefringence of the spindle in living cells. The appearance and disappearance, as well as the number concentration of microtubules seen with the electron microscope after fixation with birefringence-maintaining fixative were found to parallel the (form) birefringence of the spindle fibers measured in living cells (Sato et al., 1975).

Finally then, the main linear fibrils that make up the spindle fibers could be equated with microtubules, which exhibited assembly/disassembly properties similar to the labile spindle fibers in dynamic equilibrium with their subunits (tubulin) in living cells.

Since the late 1960 's, following the discovery of dynein (Gibbons and Rowe, 1965), the focus on force generation for mitosis in most laboratories shifted to translocator motor proteins that generate sliding forces between or along microtubules (McIntosh et al., 1969; McIntosh and Koonce, 1989; McIntosh and Pfarr, 1991; Sawin and Endow, 1993). Since the discovery of kinesin in 1985, at least 52 kinesin-related proteins and 
A

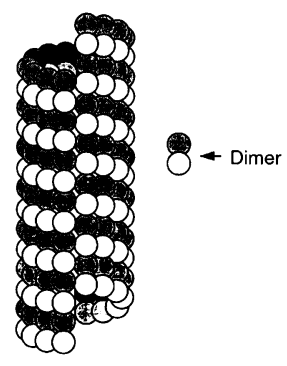

B

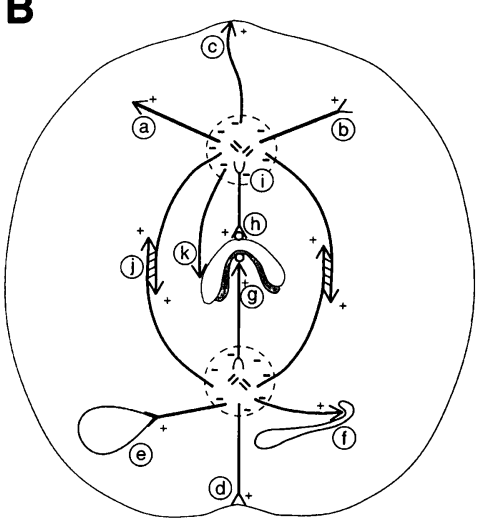

Figure 2. Microtubule structure, polarity, dynamic instability, and probable sites of force generation associated with microtubule assembly/disassembly. (A) Sketch of the structure of a 13-protofilament microtubule showing the head-to-tail alignment of the $\alpha$ and $\beta$ tubulin dimers along the protofilaments. A single $4 \times 8-\mathrm{nm}$ tubulin dimer is shown on the right. (Modified from Mandelkow et al., 1986; Song and Mandelkow, 1995). (B) Schematic summary of how microtubule assembly/disassembly is likely to be involved with chromosome movement and centrosome positioning in living cells. Some microtubules with free ends grow (arrowheads) at a steady pace, incorporating tubulin-GTP subunits at their free plus ends (a). At other moments, an elongating microtubule suddenly switches to shortening and as it disassembles, also at its plus end (forked), it releases tubulin-GDP subunits (b). Some attached to the cell cortex (c) continue to grow, push against the cortex and centrosome, and deform the cell surface as well as the microtubule itself. Others attach to the cell cortex, start to shorten at the attachment site (d), and exert a pulling force on the cell surface and the centrosome. Microtubules whose plus ends attach to vesicles and other organelles deform the organelles so that they point toward the centrosome (by the organelles being pulled against obstructing structures) as the plus end depolymerizes and pulls the organelles centripetally (e). Growth of plus ends at the organelle attachment site pushes the organelle away from the pole (f). The plus ends of microtubules attached to the chromosome at the kinetochore can continue to grow at that attachment site $(\mathrm{g})$ and contribute to an increase in kinetochore to pole distance, or as they disassemble at the kinetochore (h) or at the pole (i), they can exert a tension between the kinetochore and the center. Plus end growth of overlapping microtubules from opposite spindle poles helps to push the poles apart (j). Arms of chromosomes may also be pushed away from the center by growing plus ends (k). Modified from Inoué (1990).

a cytoplasmic form of dynein have been found in living cells (Goldstein, 1993; Sawin and Endow, 1993; Vallee, 1993; Goodson et al., 1994). Several motor proteins have been found, by immuno-chemical staining, to co-localize with specific regions of chromosomes, kinetochores, centrosomes, and spindle fiber microtubules or membrane vesicles (McIntosh and Pfarr, 1991; Goldstein, 1993; Sawin and Endow, 1993; reviewed in Fuller, 1995). In addition, genetic mutants of motor proteins, studied in particular in yeast and Drosophlia, have been shown to suppress or modify mitosis, indicating that they are important for spindle assembly, separation of the spindle poles, and chromosome movement (reviewed in: Goldstein, 1993; Sawin and Endow, 1993; Hoyt, 1994; Snyder, 1994; Fuller, 1995).

Despite this justified shift in emphasis toward seeking the roles of motor proteins in chromosome movements for the past two and a half decades, interest in the role played by assembly and disassembly of microtubules in force generation for mitosis and related movements (Figure 2B) has been rekindled in recent years. It is probable that multiple mechanisms and force producers have evolved to ensure accurate segregation of chromosomes. Both microtubule assembly/disassembly and microtubule motors could contribute together or in different ways in the production and regulation of forces, both in mitosis and other microtubule-dependent movements. For example, there is now evidence that both active and inactive microtubule motor proteins can couple cargo to depolymerizing microtubule ends (see Sections 4, 6, and 7).

In the following sections, we review the observations and experiments that have led to the renewed interest in the assembly/disassembly mechanism for force production, which had earlier been considered by many to be counter intuitive and thus untenable. In this discussion, we focus on how the acts of assembly and disassembly in and of themselves could contribute to generating forces required for mitosis and related movements. In this light, we discuss possible force-generating mechanisms at the kinetochore and how these mechanisms may also regulate the velocity and onset of anaphase chromosome movement. We begin with the discovery of microtubule "dynamic instability," because it both accounts for the dynamic nature of the spindle and it is fundamental to force generation by assembly/disassembly.

\section{MICROTUBULE STRUCTURE, POLARITY, AND DYNAMIC INSTABILITY}

Microtubules are linear, polarized, polymers of tubulin dimers (Figure 2A). Each dimer is a $100-\mathrm{kDa}$ complex of closely related $\alpha$ and $\beta$ tubulin polypeptides. The 24-nm diameter cylindrical wall of the microtubule is made up of protofilaments of tubulin dimers. Cytoplasmic and spindle microtubules typically have 13 protofilaments. One end of a microtubule has a crown of $\alpha$ tubulin while the other end has a crown of $\beta$ tubulin (Mandelkow et al., 1986; Song and Mandelkow, 1995).

The "head-to-tail" arrangement of the dimers along the protofilaments gives the microtubules an intrinsic structural polarity. In the early 1980 's, several structural methods were developed to determine microtubule polarity (Heidemann and McIntosh, 1980; Telzer and Haimo, 1981; McIntosh and Euteneuer, 1984). In ciliary axonemes, all microtubules have the same polarity; the ends distal to the basal body are called "plus" while those proximal are called "minus." Sim- 
ilar methods were used to show that during mitosis the centrosome at each spindle pole nucleates microtubules with their plus ends pointing away from the pole (Figure 2B). A subset of these, called kinetochore microtubules, become attached by their plus ends to the kinetochore regions of the chromosomes (Figure $2 \mathrm{~B}, \mathrm{~g}$ and $\mathrm{h}$ ). It is not yet clear if plus ends have crowns of $\alpha$ or $\beta$ tubulin; there is evidence favoring both possibilities (Oakley, 1992; Mitchison, 1993; Song and Mandelkow, 1995). Most of the kinesin-related proteins have been shown to be plus end-directed motors (Walker and Sheetz, 1993; Goodson et al., 1994), but members of one group, the ncd family, are minus end-directed like the dyneins (McDonald et al., 1990; Walker et al., 1990; Vallee, 1993; Endow et al., 1994).

A big surprise in the early 1980 's was evidence that polymerized tubulin throughout the mitotic spindle exchanges rapidly with the pool of unassembled tubulin dimers. In the laboratories of McIntosh and Salmon (Salmon et al., 1984; Saxton et al., 1984; Wadsworth and Salmon, 1986), fluorescently labeled tubulins, added to the cellular tubulin pool, were used as a tracer, in combination with measurements of fluorescence redistribution after photobleaching, to measure the rate of microtubule turnover at steady state. These studies showed that the half-life of tubulin turnover in the mitotic spindle of sea urchins and mammalian cells is fast, occurring within 20-60 s. Subsequent studies (Mitchison et al., 1986) showed that this fast turnover is the property of microtubules whose plus ends are free; kinetochore microtubules are differentially stable (Brinkley and Cartwright, 1975; Salmon et al., 1976; reviewed in Salmon, 1989) with half-lives of several minutes (Mitchison et al., 1986; Mitchison, 1989; Cassimeris et al., 1990). Previously, the assembly/disassembly of microtubules in vitro had been shown to occur only at the ends of microtubules (Margolis and Wilson, 1978; Bergen and Borisy, 1980; Gelfand and Bershadsky, 1991). How then could tubulin subunits appear to be exchanging rapidly throughout the array of spindle microtubules?

The origin of this fast turnover turned out to be a unique property of microtubule assembly called dynamic instability, which was discovered by Mitchison and Kirschner $(1984 a, b)$. In an in vitro study, they examined how microtubule lengths become redistributed in a population self-assembled from pure tubulin. The key observation was that in a population of microtubules whose average length was declining, a subset of microtubules continued to grow longer. On this basis, they proposed that microtubule ends, in a population at steady-state assembly, have the ability to alternate between persistent phases of growth and shortening. Subsequently, the dynamic instability of individual microtubule ends was directly seen in vitro, in real-time, using dark-field microscopy by Horio and Hotani (1986), and by video-enhanced DIC (differential interference, or Normarski, contrast) microscopy by Walker et al. (1988) (Figure 3, B-D). The growth and shortening (shrinking) phases of dynamic instability are persistent because thousands of tubulin subunits add during a single growth phase or dissociate during a single shortening phase. The abrupt transition between growth and shortening is termed catastrophe, while the switch from shortening back to growth is termed rescue (Walker et al., 1988) (Figure 3A).

In living cells, both fluorescence microscopy and video-enhanced DIC microscopy have been used to measure the kinetics of dynamic instability for individual microtubule plus ends (Gelfand and Bershadsky, 1991; reviewed in Caplow, 1992; Erickson and O'Brien, 1992; Wadsworth, 1993). In interphase and mitotic vertebrate cells, growth velocity of free ends is about $7-14 \mu \mathrm{m} / \mathrm{min}$, and shortening velocity is about $20 \mu \mathrm{m} / \mathrm{min}$ (Figure 4, A and B, left) (Cassimeris $\mathrm{et}$ al., 1988b; Hayden et al., 1990; Spurck et al., 1990; Shelden and Wadsworth, 1993). In interphase, microtubules become very long and have lifetimes of many minutes. In comparison, spindle microtubules are short and non-kinetochore microtubules have lifetimes of $1 \mathrm{~min}$ or less. This change in microtubule length and dynamics between interphase and mitosis depends mainly on changes in the transition frequencies of dynamic instability, catastrophe, and rescue (Gliksman et al., 1993).

Interestingly, the frequencies of catastrophe and rescue have been shown to depend somehow on the kinase activity of the cell cycle regulator, mitosis-promoting factor (MPF; the active form of $\mathrm{p} 34^{\mathrm{CDC} 2}$-cyclin B complexes). In interphase, MPF kinase activity is low. Catastrophes occur, but rescue is more frequent, and microtubules achieve long lengths and rarely shorten all the way back to the spindle poles (Figure 3C) (Cassimeris et al., 1988b; Belmont et al., 1990; Gliksman et al., 1992; Simon et al., 1992; Verde et al., 1992). Upon activation of MPF activity in mitosis or inhibition of phosphatase activity by okadaic acid in interphase, the frequency of catastrophe increases and rescue becomes rare (Figure 3D) (Belmont et al., 1990; Gliksman et al., 1992; Verde et al., 1992). In the spindle, when plus ends switch from growth to shortening, they appear to shorten all the way back to the spindle poles, where nucleation and regrowth occurs (Figure 4, A and B, left) (Mitchison et al., 1986; Wadsworth and Salmon, 1986). Phosphorylation of microtubule-associated proteins (MAPs) by MPF appears to be one mechanism that induces the loss of rescue in mitosis (Ookata et al., 1995).

For the thermodynamic analysis of the spindle dynamic equilibrium, Inoue assumed that tubulin subunits exchanged all along the length of spindle fibers (Inoué, 1959-1964). Although there is evidence that tubulin can very slowly dissociate from the walls of 
A Microtubule Dynamic Instability
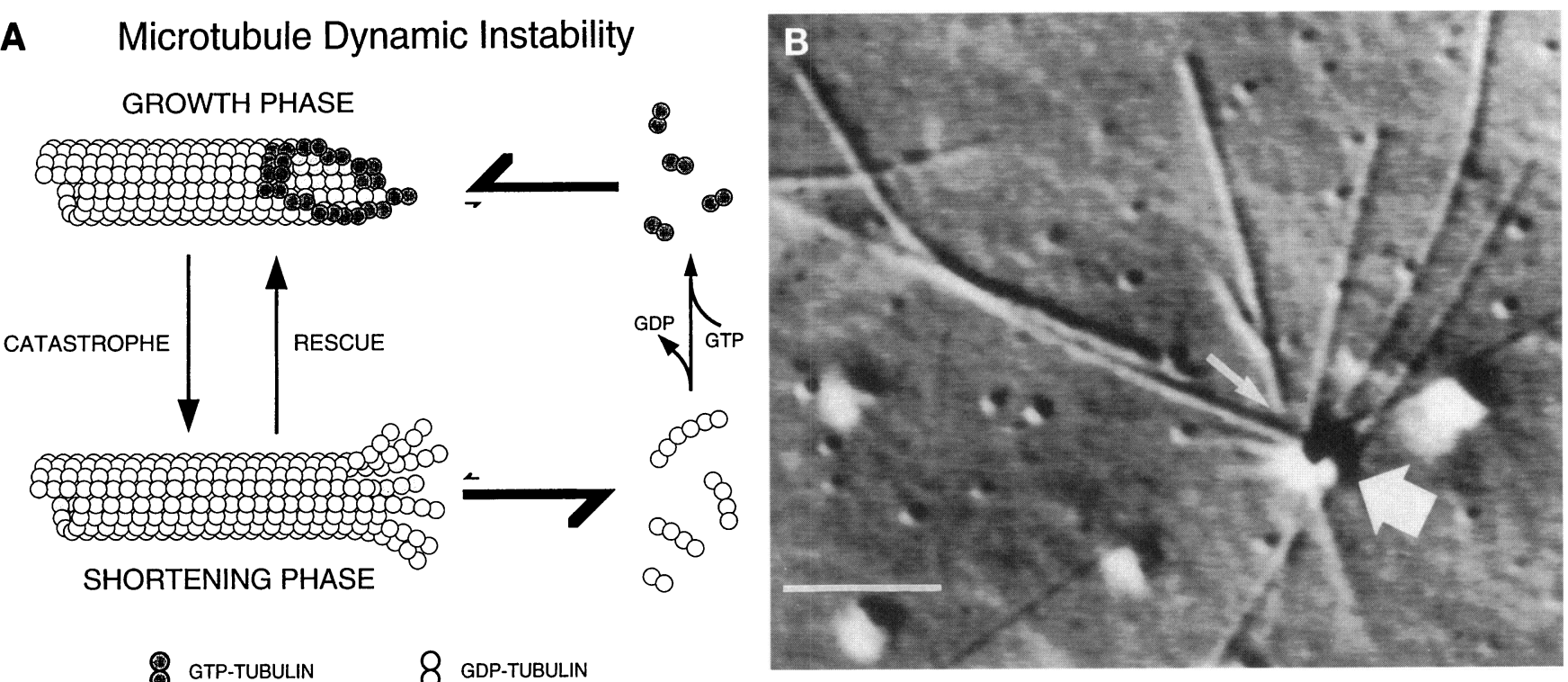

8 GtP-tubulin 8 GDP-tubulin

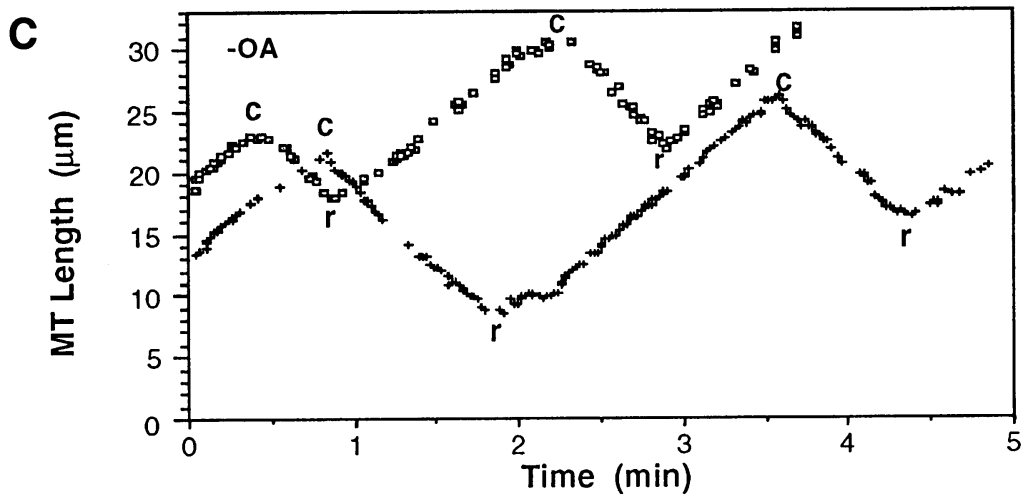

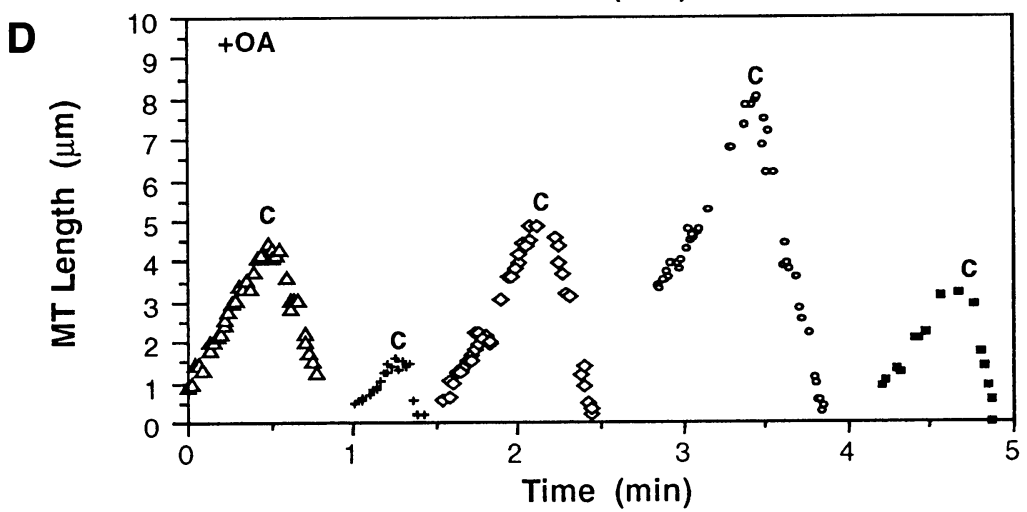

Figure 3. (A) Model for the mechanism of microtubule dynamic instability. See text for details. (B) Video-enhanced DIC micrograph of microtubules nucleated from a centrosome (large arrow) in interphase cytoplasmic extracts of sea urchin eggs. Microtubule motors on the coverslip occasionally pull the minus ends of microtubules from the centrosomes (small arrow). Scale equals $5 \mu \mathrm{m}$. (C) Dynamic instability of microtubules in panel $B$ showing the constant velocity growth and shortening phases and the frequent catastrophes (c) and rescues (r). (D) In extract treated with okadaic acid (OA) to block phosphatase 1 and $2 \mathrm{~A}$ activity, microtubules retract to much shorter lengths than in panel $C$ because no rescues occur. Different symbols represent different microtubules. Panels B-D are from Gliksman et al. (1992). microtubules (Dye et al., 1992), there is no evidence to date that rapid and extensive tubulin exchange with microtubules occurs at sites other than at their ends. The dynamic instability of microtubule plus ends does make the spindle dynamic and it does explain the tubulin subunit turnover throughout the spindle fibers.
Microtubule dynamic instability fundamentally depends on the hydrolysis of GTP bound to tubulin as initially proposed by Mitchison and Kirschner $(1984 a, b)$. Figure 3A summarizes the current view of how GTP hydrolysis changes the conformation of tubulin and generates dynamic instability (Stewart et al., 1990; Carlier, 1991; Walker et al., 1991; Caplow, 1992; 


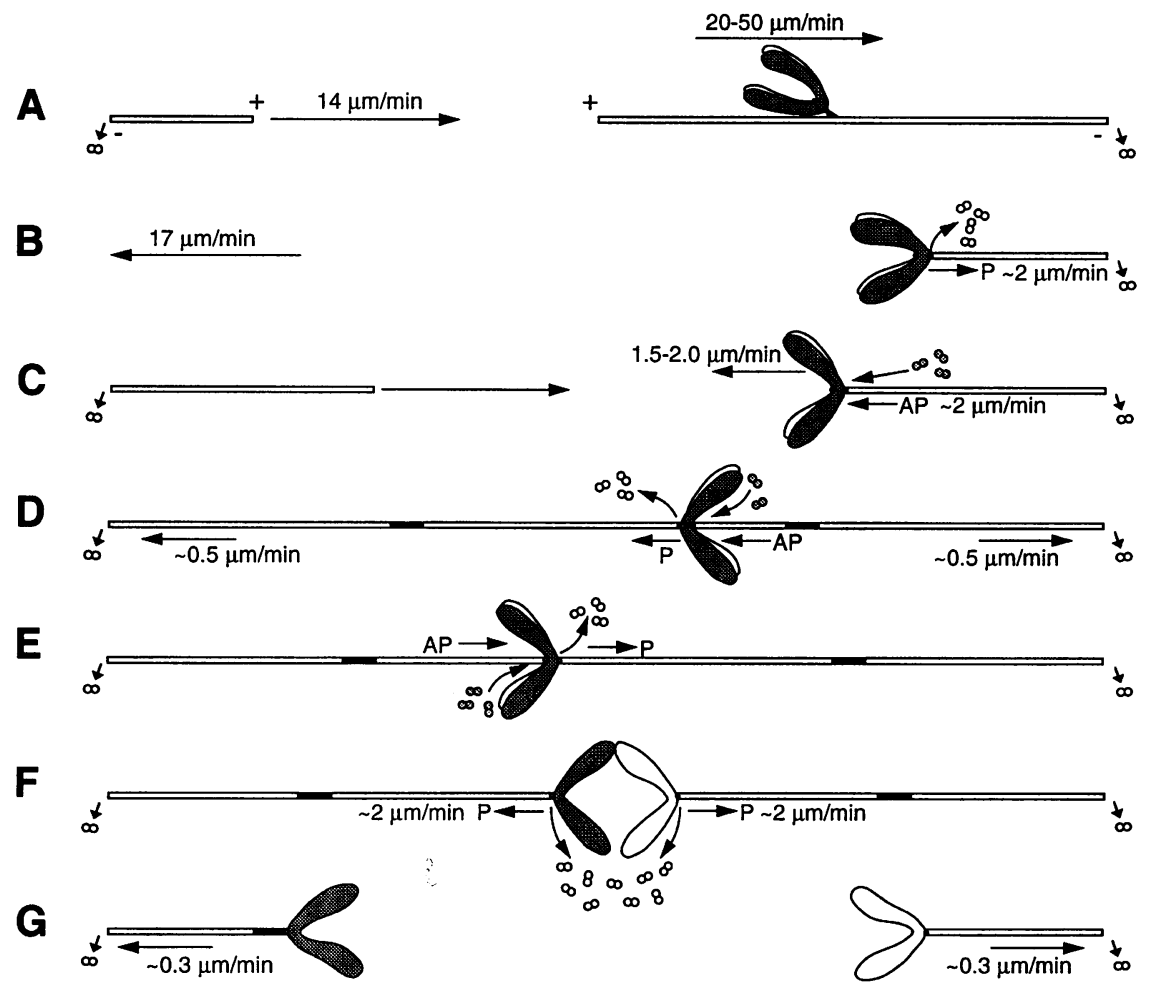

Figure 4. Schematic of kinetochore motility and microtubule assembly/disassembly in vertebrate mitotic cells. The kinetochore of a chromosome may initially become attached to the side of a polar microtubule and slide rapidly along its wall (A). Once the tips of microtubules attach to a kinetochore, the chromosome is slowly pulled poleward (B) or pushed away from the pole (C) alternating every few minutes. Once the sister kinetochore becomes attached to microtubules from the opposite pole (D), it persists in poleward movement $(\mathrm{P})$ while the initially attached kinetochore persists in away from the pole movement (AP) toward the spindle equator. Near the equator, sister kinetochores continue to alternate between poleward and away from the pole movements (E) until chromosome separation at the onset of anaphase (F). Then both sister kinetochores persist in poleward movement $(G)$, although occasional episodes of away from the pole oscillation occur. Fluorescent marks (dark bars) made on kinetochore fibers in prometaphase, metaphase, and anaphase reveal only slow poleward flux of kinetochore microtubules (D-G). Small curved arrows show the microtubule shortening at the kinetochore coupled to poleward movement, or microtubule growth at the kinetochore coupled to away from the pole movement, or slower microtubule shortening at the polar minus ends coupled to the poleward flux. Velocities indicated in the figure include contributions from flux.
Erickson and O'Brien, 1992; Caplow et al., 1994; Drechsel and Kirschner, 1994).

The phase of a microtubule (growth or shortening) is thought to be determined by the presence of GTP or GDP on the tubulin subunits at the end of the polymer. There is one exchangeable site for GTP on $\beta$ tubulin (E site) that must be occupied by GTP for dimer polymerization. The rate of polymerization depends on the concentration of GTP-bound tubulin (tubulin-GTP) and the binding constant for growing ends. As tubulin-GTP dimers are incorporated into the microtubule end, GTP is hydrolyzed to GDP and phosphate is released. This produces a core lattice of tubulin-GDP dimers capped at the end by newly associating tubulin-GTP dimers.

A catastrophe is thought to occur when the terminal tubulin-GTP cap is lost through hydrolysis or dissociation. Loss of the cap substantially inhibits tubulinGTP association and allows rapid dissociation of the labile core of tubulin-GDP dimers. Rescue, from the shortening phase back to the growing phase of dynamic instability, is thought to occur when the end becomes re-stabilized by a new cap of tubulin-GTP.

As predicted by the model in Figure 3A, hydrolysis of GTP is not required for microtubule assembly, but it is required for dynamic instability. Microtubules assembled from tubulin bound to a slowly hydrolyz- able analogue of GTP (GMPCPP) grow at rates typical of tubulin-GTP, but they do not exhibit catastrophes and shortening phases (Hyman et al., 1992b; Caplow et al., 1994). Tubulin-GMPCPP microtubules also shorten in the absence of tubulin at a rate 1000 -fold or more slower than do tubulin-GDP microtubules (Caplow et al., 1994).

The tubulin-GTP cap appears to be confined to the growing tip. When microtubules are assembled from tubulin-GTP, cutting off the growing tip at plus ends with a microbeam induces immediate shortening of the newly exposed plus cut end (Walker et al., 1989). Alternatively, when microtubules are diluted to block tubulin-GTP association, within seconds they loose their terminal stabilizing caps and convert to the shortening phase (Voter and Erickson, 1991; Walker et al., 1991). A brief pulse of tubulin-GMPCPP before dilution is sufficient to cap and stabilize the otherwise labile core of tubulin-GDP (Drechsel and Kirschner, 1994). So far, biochemical methods have been unable to detect any unhydrolyzed GTP (E-site) in microtubules (Stewart et al., 1990; Erickson and O'Brien, 1992). These kinetic and biochemical assays indicate that the tubulin-GTP stabilizing cap may be only one or a few dimers thick at a growing end in solution (Stewart $e t$ al., 1990; Walker et al., 1991; Erickson and O'Brien, 1992; Drechsel and Kirschner, 1994). 
The hydrolysis of GTP bound to tubulin induces a conformational change in the tubulin dimer as indicated by the different structures of growing and shortening ends that can be seen in electron micrographs (Erickson, 1974; Erickson and O'Brien, 1992; Kirschner et al., 1974, 1975; Simon and Salmon, 1990; Simon et al., 1991; Mandelkow et al., 1991; Mandelkow and Mandelkow, 1992). Growing ends in solution have straight or slightly curved protofilaments that laterally contact each other (Figure 3A, Growth). In contrast, shortening ends often have protofilaments that have lost their lateral contacts, curl radially outward like "ram'shorns" and break off as curved oligimers (Figure 3A, Shortening).

Growing ends in solution also exhibit sheets of protofilaments that have not yet closed completely into a cylinder (Simon and Salmon, 1990; Simon et al., 1991; Mandelkow et al., 1991; Chrétien et al., 1995). As seen in Figures $2 \mathrm{~A}$ and $3 \mathrm{~A}$, there is a "seam" along the length of the microtubule between protofilaments where $\alpha$ and $\beta$ tubulins are laterally associated; for all other adjacent protofilaments, $\alpha$ is adjacent to $\alpha$ and $\beta$ is adjacent to $\beta$ (Mandelkow et al., 1986; Song and Mandelkow, 1995). This seam may be where cylindrical closure occurs; weaker lateral interactions there may also explain why cooling can cause cylindrical microtubules to open up into 13 protofilament sheets (Simon and Salmon, 1990). Nevertheless, the straight conformation of the tubulin-GTP dimer appears important for the tight lateral association of tubulin-GTP dimers at growing ends. For example, the growing ends of microtubules assembled from tubulin-GMPCPP have straight protofilaments and tubulin dissociation is extremely slow ( 0.1 dimers/s) (Hyman et al., 1992b, 1995; Caplow et al., 1994)

In contrast, the curvature of the protofilaments at shortening ends, where tubulin dissociation can occur at $\sim 1000$ dimers/s, is typical of the 28 degree curvature of individual tubulin-GDP protofilaments in solution (Howard and Timasheff, 1986; Melki et al., 1989). Hyman et al. (1995) have recently shown that the lattice structure of microtubules made up of tubulin-GDP and tubulin-GMPCPP are very similar. This result indicates that the strain energy in the tubulin dimer produced by hydrolysis of GTP is stored in the microtubule lattice and only becomes released when the tubulin-GDP subunits are exposed at microtubule ends.

We will later consider the potential magnitude of force and the work that can be produced by the growth and shortening phases of dynamic instability, but first we review the evidence showing that kinetochore motility in mitosis is tightly coupled to microtubule assembly dynamics.

\section{KINETOCHORE AND CHROMOSOME MOVEMENT ARE COUPLED TO MICROTUBULE ASSEMBLY/DISASSEMBLY}

It is now well documented that microtubule assembly is required to establish the bipolar spindle in prometaphase, and to increase the separation of the spindle poles during anaphase (Inoué, 1981; Salmon, 1989; McIntosh, 1994). Assembly of spindle polar microtubule arrays in prometaphase is also involved with pushing chromosome arms away from the spindle poles (Rieder et al., 1986; Rieder and Salmon, 1994; Leslie, 1992; Theurkauf and Hawley, 1992; Ault and Rieder, 1994; Cassimeris et al., 1994). These "polar ejection forces" or "polar winds" on the arms (Figure 2B, j) are thought to contribute to the congression of chromosomes to the metaphase plate in animal cells (Salmon, 1988, 1989; Rieder and Salmon, 1994). In addition to microtubule assembly, motor proteins bound to the chromosome arms may contribute to the polar ejection force (Theurkauf and Hawley, 1992; Murphy and Karpen, 1995). In this connection, several kinesinrelated motor proteins have very recently been found to be bound to chromosome arms: nod in Drosophila (Afshar et al., 1995); chromokinesin in chicken tissue cells (Wang and Adler, 1995), and Xklp1 in Xenopus embryos (Vernos et al., 1995). It will be interesting to know the polarity of their movement along microtubules and how much they function in generating the polar ejection forces.

The assembly dynamics of kinetochore microtubules are essential for fully understanding the movements of chromosomes relative to their spindle poles (Figure 4, B-G; see also Figure 9). Ultrastructural studies of vertebrate cells by Rieder (1981) and McDonald et al. (1992) have shown that many if not most kinetochore microtubules extend all the way between the spindle pole and the kinetochore where they penetrate the outer layer of the trilaminate kinetochore. Vertebrate kinetochores on average capture about 20-25 microtubules (Rieder, 1982). As chromosomes move toward the spindle equator during congression, the microtubules attached to sister kinetochores increase and decrease in length, until they achieve approximately similar lengths when the chromosomes arrive near the equator (Figure 4E). Upon sister chromosome separation at the onset of anaphase, the kinetochore microtubules shorten as their chromosomes move poleward, led by their kinetochores and centromere region (Figure 4, $\mathrm{F}$ and $\mathrm{G}$ ).

In addition to the major shifts in the lengths of kinetochore microtubules during congression and anaphase, high resolution video microscopy by Skibbens et al. (1993) and Cassimeris et al. (1994) has shown that sister kinetochores in vertebrate tissue cells oscillate back and forth over 1- to $3-\mu \mathrm{m}$ dis- 
tances relative to their spindle poles throughout mitosis following their attachment to microtubule plus ends (Figure 4, B-G). An attached kinetochore exhibits poleward movement at a constant velocity of 1 - to $3-\mu \mathrm{m} / \mathrm{min}$, then abruptly switches to constant velocity away from the pole movement. The direction of movement of a kinetochore can be independent of the movement of the sister kinetochore or the chromosome arms. This switching of the kinetochore between poleward and away from the pole motility states has been termed "kinetochore directional instability" (Skibbens et al., 1993).

During kinetochore directional instability, we find that the centromere region of the chromosome with its apical kinetochore protrudes poleward during poleward movement of the chromosome. The centromere region shortens or dimples inward as the chromosome moves away from the spindle pole (Cassimeris et al., 1994; Skibbens et al., 1993, 1995). These and related observations by Bajer (1982) and others (reviewed in Rieder and Salmon, 1994) strongly suggest that localized pulling and pushing forces applied to the kinetochore are primarily responsible for movement of the chromosome toward and away from the spindle pole once microtubules have become attached to the kinetochore; the polar ejection forces only contribute to push arms away from the pole.

Although the fact that localized forces act on the chromosome's kinetochore and are associated with shortening and growth of microtubules appears to be well established, this still leaves open the question of where the forces for mitotic chromosome movement are generated. An important clue to this question, as well as to the nature of the force-generating mechanism, is provided by studies that reveal the site(s) of kinetochore microtubule assembly and disassembly, as discussed next.

The sites of kinetochore microtubule growth and shortening have been determined by Borisy, Mitchison, Salmon, Wadsworth, and their coworkers by examining the sites at which labeled tubulin is incorporated into kinetochore microtubules (Mitchison et al., 1986; Mitchison, 1988; Wadsworth et al., 1989; Wise et al., 1991; Sheldon and Wadsworth, 1992). Alternatively, the positions (and motility, if any) of fluorescent tubulin markers, placed along a limited stretch of the kinetochore microtubules were monitored (Wadsworth and Salmon, 1986; Gorbsky et al., 1987, 1988; Cassimeris et al., 1988a; Mitchison, 1989; Cassimeris and Salmon, 1991; Centonze and Borisy, 1991; Mitchison and Salmon, 1992).

The general picture that has emerged for vertebrate tissue cells is diagrammed in Figure 4, B-G. All movement of kinetochores away from the pole is coupled to assembly of kinetochore microtubules at the kinetochore. Most kinetochore poleward move- ment, either during congression or anaphase- $\mathrm{A}$, is coupled to disassembly of kinetochore microtubules, again at the kinetochore. A minor fraction of kinetochore poleward movement is coupled to a slow $(0.3-0.5 \mu \mathrm{m} / \mathrm{min}$ in newt cells) poleward flux (Figure 4, D-G) of kinetochore microtubules as they disassemble at their minus ends at the spindle poles.

In early anaphase, available data indicate that the bulk of kinetochore poleward movement occurs at 1to $3-\mu \mathrm{m} / \mathrm{min}$ velocity along relatively stationary $\mathrm{ki}-$ netochore microtubules (Gorbsky et al., 1987, 1988; Mitchison and Salmon, 1992) (Figure 4, F). In late anaphase, the microtubules are no longer disassembled at the kinetochore (in newt cells), but the chromosomes continue to move poleward at the slow steady rates exhibited by the poleward flux of the kinetochore microtubules $(0.3 \mu \mathrm{m} / \mathrm{min}$ in newt cells, Figure 4, G) (Mitchison and Salmon, 1992).

Thus, two mechanisms have evolved for growth and shortening of kinetochore microtubules: those associated with plus end assembly/disassembly at the kinetochore, and those associated with minus end disassembly near the poles. In vertebrate tissue cells, assembly/disassembly at the kinetochore before late anaphase dominates kinetochore microtubule assembly dynamics. In other cell types, minus end disassembly at the spindle poles may play a much more significant role in assembly dynamics and pulling chromosomes poleward (Forer, 1965, 1966; Mitchison and Salmon, 1992; Sawin and Mitchison, 1994; Wilson et al., 1994).

The direction of kinetochore movement is sensitive to the conditions of microtubule assembly at their plus ends (Figure 5). If in prometaphase or metaphase, microtubule assembly is blocked with drugs such as colchicine or nocodazole, kinetochores switch to poleward movement (Inoué, 1952; Cassimeris and Salmon, 1991). The kinetochore fibers shorten much as occurs in anaphase at about 2 $\mu \mathrm{m} / \mathrm{min}$, primarily disassembling at the kinetochore (Figure 5A). When a bolus of labeled tubulin is microinjected into metaphase cells, the label is incorporated into kinetochore microtubules only at the kinetochore (Mitchison et al., 1986; Mitchison, 1988; Wise et al., 1991) (Figure 5B).

In anaphase, Sheldon and Wadsworth (1992) found that microinjection of a large bolus of labeled tubulin causes all the kinetochores to reverse direction and move away from the pole. The labeled tubulin is incorporated at the kinetochore (Figure 5C). Eventually, the kinetochores switch back to anaphase poleward movement as kinetochore microtubules revert to disassembling at the kinetochores when the free tubulin concentration drops.

Taken together, these studies, and others (Rieder and Salmon, 1994), have shown that the kinetochore: 1 ) is the major site for assembly/disassembly 
Figure 5. The direction of kinetochore movement is sensitive to manipulation of microtubule assembly. (A) When metaphase cells are treated with nocodazole, kinetochores persist in poleward movement toward fluorescent marks (dark bars) on their kinetochore microtubules. (B) Microinjection of a bolus of labeled tubulin into metaphase spindles results in incorporation of labeled tubulin into kinetochore fibers at the kinetochores. (C) Microinjection of a bolus of labeled tubulin into a cell that has already entered anaphase results in incorporation of labeled tubulin at the kinetochores and movement of the kinetochores away from the poles. Eventually, as the tubulin concentration drops, the kinetochores switch back to poleward movement as microtubules disassemble at the kinetochore.

of kinetochore microtubules; 2) can abruptly switch between poleward and away from the pole motility at slow constant velocities; and 3) can switch direction of motility in response to conditions that affect microtubule assembly.

Thus, assembly/disassembly of microtubules at the kinetochore is intimately coupled to force generation for chromosome congression to the spindle equator as well as for anaphase-A segregation of chromosomes to the spindle poles (at least in vertebrate tissue cells). (The qualifier is added here because in some lower invertebrate and plant cells kinetochore microtubule poleward flux (treadmilling) and their disassembly at the minus ends may play a much more important role).
B METAPHASE
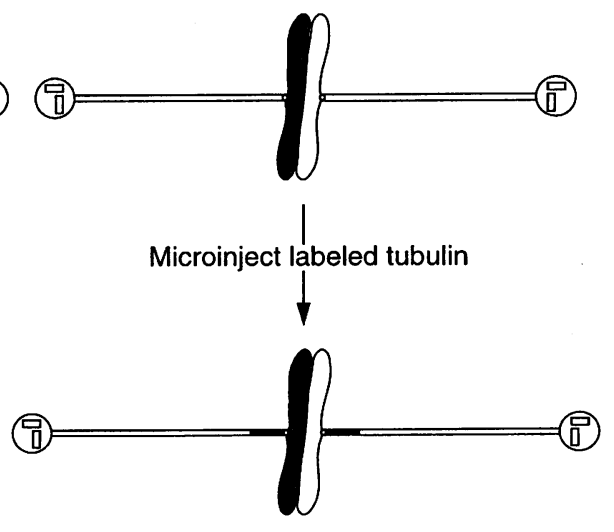
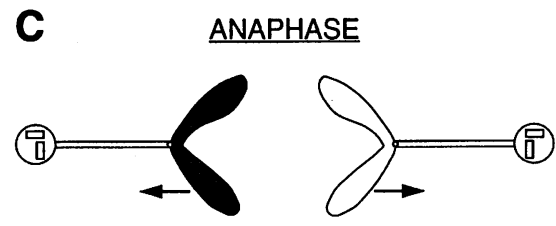

I

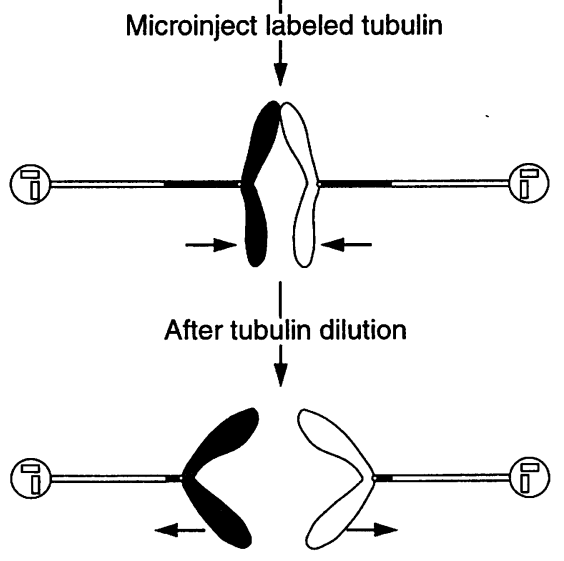

\section{KINETOCHORE MOTILITY AND RELATED FORCES MAY BE GENERATED BY MOTOR PROTEINS, BY MICROTUBULE ASSEMBLY/DISASSEMBLY, OR BY BOTH}

Both microtubule-dependent motor proteins as well as microtubule assembly/disassembly have been proposed to contribute to force generation for kinetochore poleward and away from the pole movements and the polar ejection forces that act on the chromosome arms. The roles in force generation, attachment, or regulation played by each and how they vary in different cell types are major unresolved issues. The inventory of microtubule motor proteins at the kinetochore has only begun and little information is available about their specific functions. Both cytoplasmic dynein 
(Pfarr et al., 1990; Steuer et al., 1990) and the kinesinrelated proteins CENPE (Yen et al., 1991, 1992) and MCAK (Wordeman and Mitchison, 1995) have been localized by antibody staining to mammalian kinetochores. In the yeast, Saccharomyces cerevisiae, both genetic studies and biochemical assays indicate that the kinesin-related protein kar3p is a minus end-directed motor that may function in generating pole-directed force in mitosis (Saunders and Hoyt, 1992; Endow et al., 1994; Middleton and Carbon, 1994). In in vitro motility assays, kar3p has been shown to bind to centromere DNA and move it along microtubules (Hyman et al., 1992a). Both biochemical and genetic approaches are likely to identify other unknown microtubule-dependent motor proteins at the kinetochore (Earnshaw, 1994) that could function in kinetochore motility either in force generation or attachment to kinetochore microtubules.

One model proposed by several authors for motility generated at the kinetochore is shown in Figure 6 (Skibbens et al., 1993; Murray and Mitchison, 1994). During kinetochore poleward movement, a minus end-directed motor is active and movement is coupled to plus end disassembly of the kinetochore microtubules. During movement of the kinetochore away from the pole, a plus end motor is active and movement is coupled to plus end assembly of kinetochore microtubules.

In support of kinetochore force production by activity of motor proteins, Rieder et al. (1990) and Merdes and DeMey (1990) have reported that kinetochores slide along microtubules toward their minus ends (i.e., toward the spindle poles, Figure 4A, right) in early

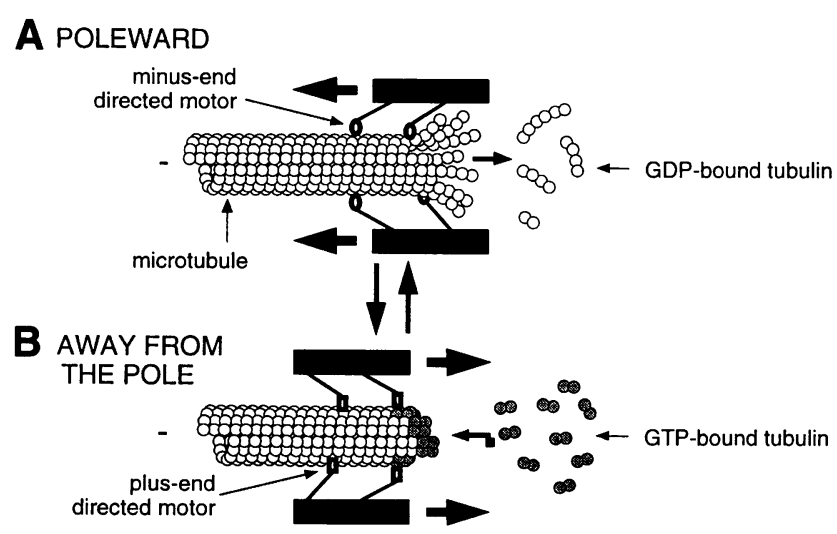

Figure 6. A model for a kinetochore motor (cf. Figure 8). An individual microtubule-binding site (cylinder section shown as two dark bars) of a kinetochore undergoing poleward movement (A) or away from the pole movement (B). During poleward movement, the microtubule ends depolymerize, releasing tubulin-GDP subunits while motors directed toward the "minus" (centrosomal) end of the microtubule are activated. During movement away from the pole, microtubules polymerize tubulin-GTP and plus end-directed motors are activated. Modified from Murray and Mitchison (1994). prometaphase before the kinetochores become attached to microtubule plus ends. This poleward translocation occurs at a fast rate of about $30-60 \mu \mathrm{m} / \mathrm{min}$ and is thought to depend on cytoplasmic dynein located at the kinetochore. Hyman and Mitchison (1991) used in vitro motility assays to show that kinetochores, on isolated metaphase chromosomes from mammalian cells, can attach to the walls of microtubules and translocate also at fast velocities in a minus direction in the presence of ATP.

Pre-treatment of isolated chromosomes with ATP $\gamma S$ promotes phosphorylation of kinetochores. In this case, ATP-dependent microtubule translocation occurs in a plus direction at slow velocities, $1-4 \mu \mathrm{m} / \mathrm{min}$ (Hyman and Mitchison, 1991). This experiment shows that slow plus end-directed motor activity is nacently present in the kinetochores and that phosphorylation can switch between minus and plus end-directed motor activity.

In living cells, the majority of kinetochore movement occurs at the plus ends of kinetochore microtubules, with the movement tightly coupled to the assembly dynamics of the kinetochore microtubule at their plus ends (Section 3). Thus a major function of the minus and plus end-directed "motor proteins" at the kinetochore could be to maintain attachment to shortening and growing plus ends of the microtubules rather than to produce sliding forces (Skibbens et al., 1993; Desai and Mitchison, 1995; Lombillo et al., 1995a). The pulling and pushing forces could in turn be produced by disassembly and assembly reactions. As discussed above (Figure 5), blocking microtubule assembly induces persistent movement of the kinetochore toward the spindle pole (or shortening of the kinetochore to pole distance); promoting assembly by raising the local tubulin concentration induces persistent motion of the kinetochore away from the pole. (Whether there are accompanying changes in kinetochore phosphorylation is unknown.) These experimental results clearly show that the direction of kinetochore motility can be controlled by changing the assembly state of the plus ends of the kinetochore microtubules: growth induces movement away from the pole, shortening induces poleward movement.

Taken together, these observations strongly suggest both the presence of "motor proteins" at the kinetochore and an intimate coupling of microtubule assembly/disassembly to kinetochore movement. We shall now examine further in vitro evidence that microtubule assembly of itself can generate pushing forces, that disassembly can generate pulling forces, and that active and inactive motor proteins can couple cargo to depolymerizing microtubule ends. 


\section{IN VITRO EVIDENCE FOR PUSHING BY MICROTUBULE ASSEMBLY}

There is growing evidence that the polymerization of microtubules as well as actin filaments can push. Liposomes encapsulating either tubulin dimers (Miyamoto and Hotani, 1988; Hotani and Miyamoto, 1990; Fygenson, 1995) or G-actin (Cortese et al., 1989; Janmey et al., 1992; Miyata and Hotani, 1992) have been shown to become extended when either of these subunit proteins are induced to polymerize inside the liposome. Fygenson (1995), in particular, found conditions where microtubule dynamic instability persists within pure lipid vesicles. The membrane is pushed outward into narrow protrusions during the growth phase (Figure 7A), which retract during the shortening phases of dynamic instability.

More recently, Waterman-Storer et al. (1995) have found that membranes (mainly endoplasmic reticulum) from undiluted extracts of Xenopus eggs become attached to growing plus ends of microtubules. Growth at the attachment site extends these membranes into narrow tubes at velocities typical of free plus end growth rates, $\sim 20 \mu \mathrm{m} / \mathrm{min}$ (Figure 7B). Addition of inhibitors of microtubule motor translocation (5 mM AMPPNP, $250 \mu \mathrm{M}$ orthovanadate, or ATP depletion), which block sliding movement along microtubules (Allan and Vale, 1991, 1994), has no effect on the velocity of membrane extension by microtubule growth. These results show the following: 1) membranes of endoplasmic reticulum have attachment sites for plus microtubule ends, presumably on their outer (cytosol) surfaces, and 2) these membrane microtubule tip attachment complexes are able to maintain attachment to ends that are growing at about 540 dimers/s.

\section{IN VITRO EVIDENCE FOR PULLING BY MICROTUBULE DISASSEMBLY}

Koshland et al. (1988) were the first to provide in vitro evidence that microtubule plus ends can remain attached to kinetochores on isolated chromosomes as the microtubule plus ends shorten in the presence or absence of ATP (Figure 7C). Coue et al.

\section{A DYNAMIC INSTABILITY OF LIPOSOME CONTAINING PURE TUBULIN}

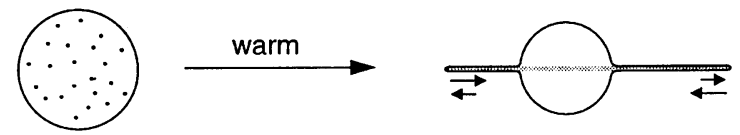

B XENOPUS CYTOPLASMIC EXTRACTS

Figure 7. In vitro evidence for pushing and pulling forces generated by microtubule assembly/disassembly. (A) Microtubule undergoing dynamic instability within liposomes reversibly pushes the membrane into narrow protrusions. (B) In Xenopus egg cytoplasmic extracts, growing microtubule plus ends become attached to membranes and push them into long tubes. When catastrophe takes place, the depolymerizing end then pulls the membrane tubes toward their minus ends, which are anchored to the coverslip. (C) Microtubules attached by their plus ends to isolated chromosomes shorten at their plus end attachment sites as indicated by fluorescent marks on the microtubules. (D) Chromosomes attached at their centromere (kinetochore?) region to the walls of microtubules grown from protozoan pellicles are pulled toward the pellicle as the microtubule plus end, attached to the chromosome, is depolymerized by dilution of the tubulin. (E) Plastic beads coated with kinesin initially translocate toward microtubule plus ends. But upon tubulin dilution in a high salt buffer, the beads become pulled in a minus end direction toward the pellicle when the beads reach, and become attached, to the microtubule plus ends.

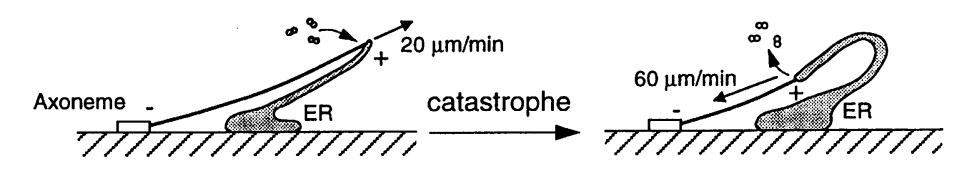

Plus-end growth pushes

Plus-end shortening pulls

C ISOLATED CHROMOSOMES

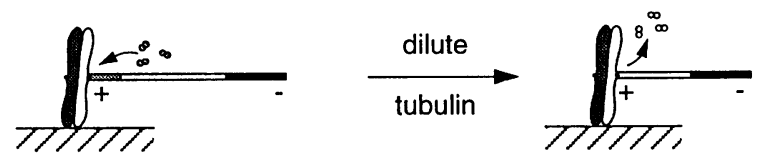

D PELLICLE ASSAY

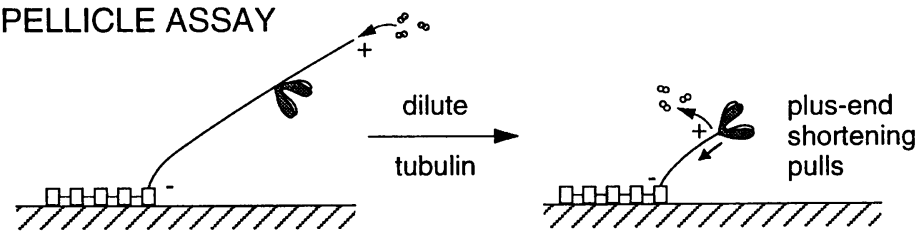

E MOTOR PROTEINS ON BEADS

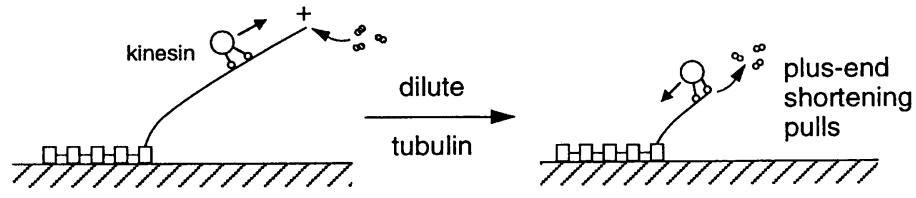


(1991) have investigated this issue further by using a novel in vitro motility assay (Figure 7D). In their assay, microtubules are grown from pure tubulin onto the basal bodies of isolated protozoan pellicles attached to the inner surface of a coverslip. This produces a high density of long microtubules extending many microns and all with their plus ends pointing away from the stationary pellicle. Isolated chromosomes are added by perfusion until they bind to the microtubule wall. Then the microtubules are made to disassemble by perfusion with buffer lacking tubulin. When the shortening end of a microtubule reached the centromere region of the attached chromosome, the chromosome began moving toward the pellicle attached to the end of the microtubule as the end continued to disassemble at velocities similar to free ends (i.e., at $30-40 \mu \mathrm{m} /$ min). Chromosomes were pulled to the pellicle, with or without ATP, against drag forces estimated at $\sim 10 \mathrm{pN}$ (Coue et al., 1991).

In another series of experiments, Lombillo et al. (1995a) attached several different types of microtubule motor proteins to $1-\mu \mathrm{m}$ diameter plastic beads (Figure $7 \mathrm{E}$ ). Beads with active axonemal dynein, cytoplasmic dynein, or kinesin translocate along microtubules in standard motility buffers with ATP, but they did not remain attached once they reached the microtubule's shortening end.

Under conditions that weakened motor attachment to the microtubule lattice, however, the beads behaved differently. Examples include axonemal dynein inhibited with orthovanadate, and an inactive hybrid molecular complex with a kinesin motor domain attached to the tail of a kinesin-related protein, ncd. These beads did not show their normal unidirectional gliding activity, but both remained attached to shortening ends of microtubules, in the presence or absence of ATP.

Finally, increasing salt concentration to reduce binding strength to the microtubule lattice also allowed native kinesin to remain attached to a shortening end. Remarkably, under these conditions and in the presence of ATP, the bead with native kinesin moved toward the microtubule plus end until the shortening end reached the bead. Then, the bead was dragged, attached to the shortening end, in a minus direction (Figure 7E)! These results showed that even after active translocation by the plus end-directed motor has ceased, the motor was capable of remaining attached to the shortening plus end of the microtubule, resulting in a minus end-directed motility (Lombillo et al., 1995a).

Particles and membranes in cytoplasmic egg extracts have also been observed to be pulled toward the microtubule minus ends by their attachment to depolymerizing plus ends (Gliksman and Salmon, 1993; Waterman-Storer et al., 1995). For example, in Xenopus cytoplasmic extracts (see Section 5), Waterman-Storer et al. (1995) also found that when a growing microtubule end switched spontaneously to the shortening phase of dynamic instability, membrane tubes remained attached to the microtubule end (Figure 7B). The membrane tube was pulled through the extract at velocities similar to the velocity of free end shortening, $50-60 \mu \mathrm{m} / \mathrm{min}$, whether or not inhibitors (5 $\mathrm{mM}$ AMPPNP, $250 \mu \mathrm{M}$ orthovanadate, or ATP depletion) of microtubule-dependent motor activity were present. Thus, as in the kinetochore or bead assays above, in the absence of active motor translocation, the Xenopus membranes can be pulled through cytosol attached to shortening plus ends of microtubules (which are losing dimers rapidly, at about 1600 dimers/s in the Xenopus cytoplasm).

\section{THE NATURE OF MICROTUBULE TIP ATTACHMENT COMPLEXES}

The above experiments demonstrate that microtubule growing ends can push, while shortening ends can pull without becoming detached from their load. They also show that both active and inactive motor proteins can couple objects to shortening ends, allowing rapid dimer dissociation while remaining attached to the end. Whether motor proteins, either active or inactive, can couple cargo to growing ends has yet to be demonstrated.

The actual molecules within tip attachment complexes that couple membranes or kinetochores to growing and shortening ends have not been definitely identified. Nevertheless, Lombillo et al. (1995b) have shown that antibodies to CENPE, a kinetochoreassociated, kinesin-related protein, disrupt attachment of kinetochores to shortening ends in their in vitro motility assays. The result implies that this kinetochore protein is involved in attachment. Other possible candidates include cytoplasmic dynein, MCAK, nod, XKLP1, kar3p, chromokinesin, or other as yet unknown kinesin-related proteins associated with the kinetochore.

The attachment molecules need not be active motor proteins. Microtubules have been shown to exhibit Brownian motion along their long axis, i.e., without any lateral movement when weakly bound to inactive axonemal dynein (orthovanadate inhibited) or to nonmotile kinesin-related proteins attached to glass surfaces (Vale et al., 1989; Chandra et al., 1993; Stewart et al., 1993; Lombillo et al., 1995a). These observations indicate that a sufficient concentration of nonmotor, microtubule-binding proteins might also be able to couple cargo to shortening ends. An interesting candidate is the protein CLIP 170, which has been shown by Kreis and coworkers to localize to the plus ends of microtubules in HeLa cells (Scheel and Kreis, 1991; Pierre et al., 1992). 
Also unknown are the sites on the tubulin dimer at which the TAC is attached. "Binding machines" that follow the ends of growing and shortening microtubules presumably have two features: 1) the activation energy for binding and dissociation must be low enough to allow the rapid cycles of binding and release to follow a moving microtubule end without disrupting the assembly dynamics; and 2) the binding machine must have multiple binding sites or rapid enough binding so that dissociation of

\section{A LATERAL TIP ATTACHMENT COMPLEX}

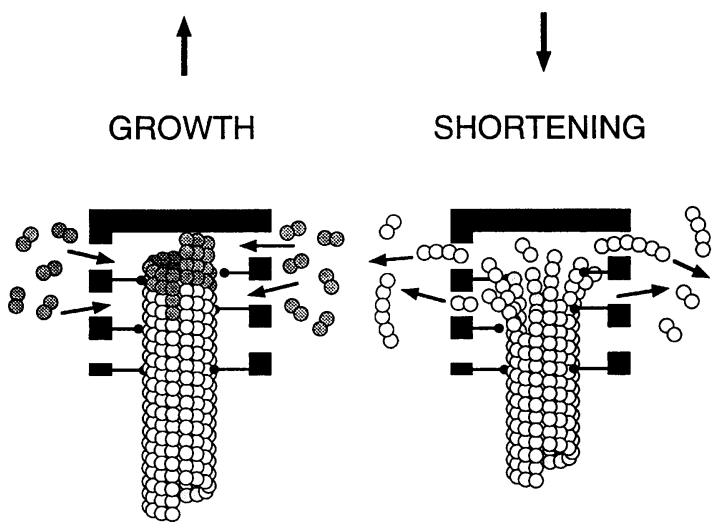

B END TIP ATTACHMENT COMPLEX
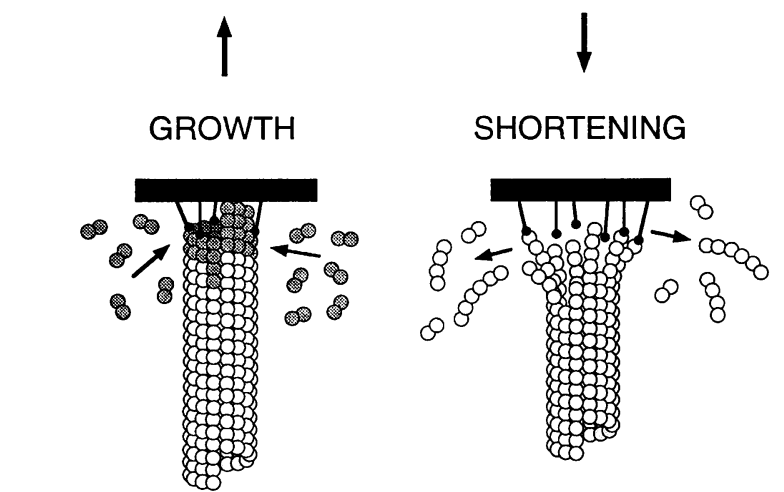

8 GtP-tubulin

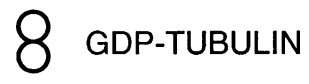

Figure 8. Models for the tip attachment complex (cf. Figure 6). (A) The tip attachment complex cups the end of the microtubule without blocking tubulin exchange while maintaining attachment to growing and shortening ends. The tip attachment complex is held by attachment molecules that weakly associate with sides of the microtubule wall. Pushing force during growth and pulling force during shortening are produced by "Brownian Rachet mechanisms" discussed in the text. (B) The tip attachment complex dynamically binds to tubulin dimers at the microtubule tip in both the growing and shortening phases of dynamic instability. a single site does not lead to detachment from a shortening end. We don't know how few these multiple sites could be. As diagrammed in Figure 8A, most models (see next section) envision some form of lateral attachment that permits translocation of the tip attachment complex over the lattice coupled to growth and shortening. However, there is no evidence to rule out the possibility that effective attachment occurs at the distal tip of the tubulin dimers at the microtubule end (Figure $8 \mathrm{~B}$ ).

\section{MODELS FOR THE MICROTUBULE ASSEMBLY/DISASSEMBLY ENGINE}

A major question is the mechanism by which the energetics of assembly/disassembly is transduced into work at the attachment site. Motion is probably generated by some type of molecular "Brownian Rachet" for either growth or shortening in which the highly irreversible addition of tubulin-GTP to growing ends and the highly irreversible dissociation of tubulin-GDP from shortening ends rectifies thermal motion of the tip attachment complex. There are several theoretical considerations about how such Brownian Rachet mechanisms can work to produce pushing during growth (Peskin et al., 1993) and pulling during shortening (Hill, 1985; Koshland et al., 1988; Mitchison, 1988; Desai and Mitchison, 1995). They are, so far, all based on some form of lateral tip attachment complex.

The growth mechanism is easier to visualize for a tip attachment complex which "cups" the growing end (Figure 8A, Growth). Within this geometry, the tight binding of tubulin at the end biases the Brownian motion of the tip attachment complex in the direction of growth.

Thermodynamically, the maximum pushing force (the stall force, F) available from the free energy of growth is related to the kinetics of tubulin association/dissociation (Hill and Kirschner, 1982; Peskin et al., 1993):

$$
F=\left(k_{\mathrm{B}} \mathrm{T} / \mathrm{d}\right) \ln \left(\mathrm{k}_{\text {on }} / \mathrm{k}_{\text {off }}\right)
$$

where $k_{B} T$ is Boltzman's constant times absolute temperature (4.1 pN-nm at room temperature), $\mathrm{d}$ is the average displacement of the microtubule end against a load $(0.61 \mathrm{~nm}$ on average for a 13-protofilament microtubule, for association or dissociation of the $8 \mathrm{~nm}$ long dimer), $\mathrm{k}_{\mathrm{on}}$ is the dimer association rate (the product of the association rate constant and the tubulin concentration), and $k_{\text {off }}$ is the dimer dissociation rate during growth. In the growth phase, Eqn. 1 predicts pushing stall forces of $\mathrm{F}=0,16,31$, and $46 \mathrm{pN}$ for ratios of $k_{\text {on }} / k_{\text {off }}=1,10,100$, and 1000 , respectively. The binding of GTP to unassembled tubulin subunits makes GTP-tubulin association with growing ends highly favored. Stall forces of at least $16 \mathrm{pN}$, and more 
likely $32 \mathrm{pN}$, are possible in cells, because MAPs promote $\mathrm{k}_{\text {on }}$ and suppress $\mathrm{k}_{\text {off }}$ (Dreschel et al., 1992; Pryer et al., 1992; Vasquez et al., 1994).

The shortening mechanism is harder to visualize. One concept as originally proposed by Hill (1985) is that cargo movement is driven by the energetics involved with maximizing the number of weak attachment sites. This movement to achieve maximum overlap of the sleeve with the microtubule wall biases Brownian motion of the tip attachment complex toward the intact portion of the microtubule as it shortens (Figure 8A, Shortening).

The outward bending of the tubulin-GDP dimers at the shortening ends may also be important for maintaining attachment and biasing Brownian motion of the TAC in the direction of shortening (Figure 8A, Shortening). This mechanism was termed the "conformational wave" model by Koshland et al. (1988) and Mitchison (1988). High resolution microscopy of growing and shortening ends attached to cargo, like kinetochores or ER membranes, may reveal how much the curvature of the protofilaments contributes to force production. In this regard, we are still in the dark ages of kinetochore structure in comparison to the high resolution view available for actin-myosin interactions in skeletal muscle (Rayment, 1993; Rayment $e t$ al., 1993).

Thermodynamically, Eqn 1 can be used to predict the potential force that can be generated by depolymerizing ends where the $\mathrm{k}_{\text {on }} / \mathrm{k}_{\text {off }}$ ratio is now the value during the shortening phase of dynamic instability. For free plus ends of microtubules assembled in vivo or in vitro, the velocity of microtubule shortening is rapid (often $>500$ dimers/s) and in vitro, velocity has been shown to be independent of tubulin concentration (Walker et al., 1988, 1991). During shortening, $\mathrm{k}_{\text {on }}$ appears near zero and $\mathrm{k}_{\text {on }} /$ $\mathrm{k}_{\text {off }}$ appears possibly 0.001 or less. From Eqn. 1, this ratio yields a potential pulling force (minus sign) of $32 \mathrm{pN}$ or more.

Hydrolysis of the GTP bound to tubulin within the microtubule is responsible for the huge change in the $\mathrm{k}_{\mathrm{o}} / \mathrm{k}_{\text {off }}$ ratio between growth and shortening phases (Section 2). As a consequence, the potential force available from the shortening phase can be estimated from the energy of GTP hydrolysis stored in the microtubule lattice (Koshland et al., 1988). Caplow et al. (1994) report that for the assembly of pure tubulin in solution, the free energy of GTP hydrolysis is $-5.18 \mathrm{kcal} /$ mol. Within the microtubule lattice he estimates an energy release of only $-0.9 \mathrm{kcal} / \mathrm{mol}$. The difference between these two values, about $4 \mathrm{kcal} / \mathrm{mol}$ or up to $26 \mathrm{pN}-\mathrm{nm} /$ dimer $(1 \mathrm{kcal} / \mathrm{mol}=6.6 \mathrm{pN}-\mathrm{nm} / \mathrm{mole}-$ cule), should be the strain energy stored in microtubule lattice from the hydrolysis of GTP. This energy is available to do work, such as producing the curvature in the tubulin-GDP protofilaments seen at shortening ends. It predicts a stall force of about $43 \mathrm{pN}$ if each 8-nm dimer biases cargo movement in the direction of shortening on the average by $0.61 \mathrm{~nm}(8 \mathrm{~nm} / 13$ protofilaments).

The above analysis provides a rough estimate of the potential forces available from either growth or shortening phases of dynamic instability, on the order of 40 $\mathrm{pN}$ or less per microtubule end. For reference, the stall force for a single kinesin molecule is about $5 \mathrm{pN}$ (Kuo and Sheetz, 1993; Hunt et al., 1994; Svoboda and Block, 1994). Nicklas (1988), using a compliant microneedle, has directly measured the force that stalls anaphase poleward kinetochore movement and kinetochore fiber shortening in meiotic grasshopper spermatocytes. This force is estimated to be about $10 \mathrm{pN}$ per kinetochore microtubule, the same order of magnitude, and less than the force available from the energy of GTP hydrolysis stored in the microtubule lattice. Direct measurements of the forces that stall microtubule growth and shortening in cell-free systems have yet to be achieved.

\section{THE KINETOCHORE AS A GOVERNOR}

The kinetochore in living cells appears to govern several different activities. These include the rates of microtubule growth and shortening at the kinetochore, the switching between kinetochore microtubule growth and shortening, and the checkpoint that controls anaphase onset.

A major puzzle is why kinetochore motility in cells is much slower $(\sim 2 \mu \mathrm{m} / \mathrm{min})$ than the growth and shortening velocities of free plus ends of microtubules in cells or plus ends attached to membrane tip attachment complexes in the Xenopus extracts (10-50 $\mu \mathrm{m} /$ $\mathrm{min})$. The rate that kinetochores move in vitro when coupled to shortening plus ends $(20-60 \mu \mathrm{m} / \mathrm{min})$ is also much faster than kinetochore motility in vivo. In other words, once attached to kinetochores in the cell, microtubules grow and shorten at a rate that is an order of magnitude slower!

This difference is clearly not due to drag forces or polar ejection forces on the chromosome arms. The velocities of kinetochore poleward and away from the pole movement is the same for kinetochores on tiny centromere fragments severed by a microbeam from the bulk of the chromosome arms (Figure 9) (Skibbens et al., 1993, 1995). So, what mechanisms limit the plus end growth and shortening rates of kinetochore microtubules inside living cells to a constant velocity of about $2 \mu \mathrm{m} / \mathrm{min}$ ?

Could the velocity be regulated by nonmotor MAPs? Neuronal MAP2 and Tau do slow the rate of microtubule shortening, but these MAPs also promote faster growth rates (Dreschel et al., 1992; Pryer et al., 1992). The Xenopus XMAP protein makes both growth and shortening velocities faster than occurs for micro- 

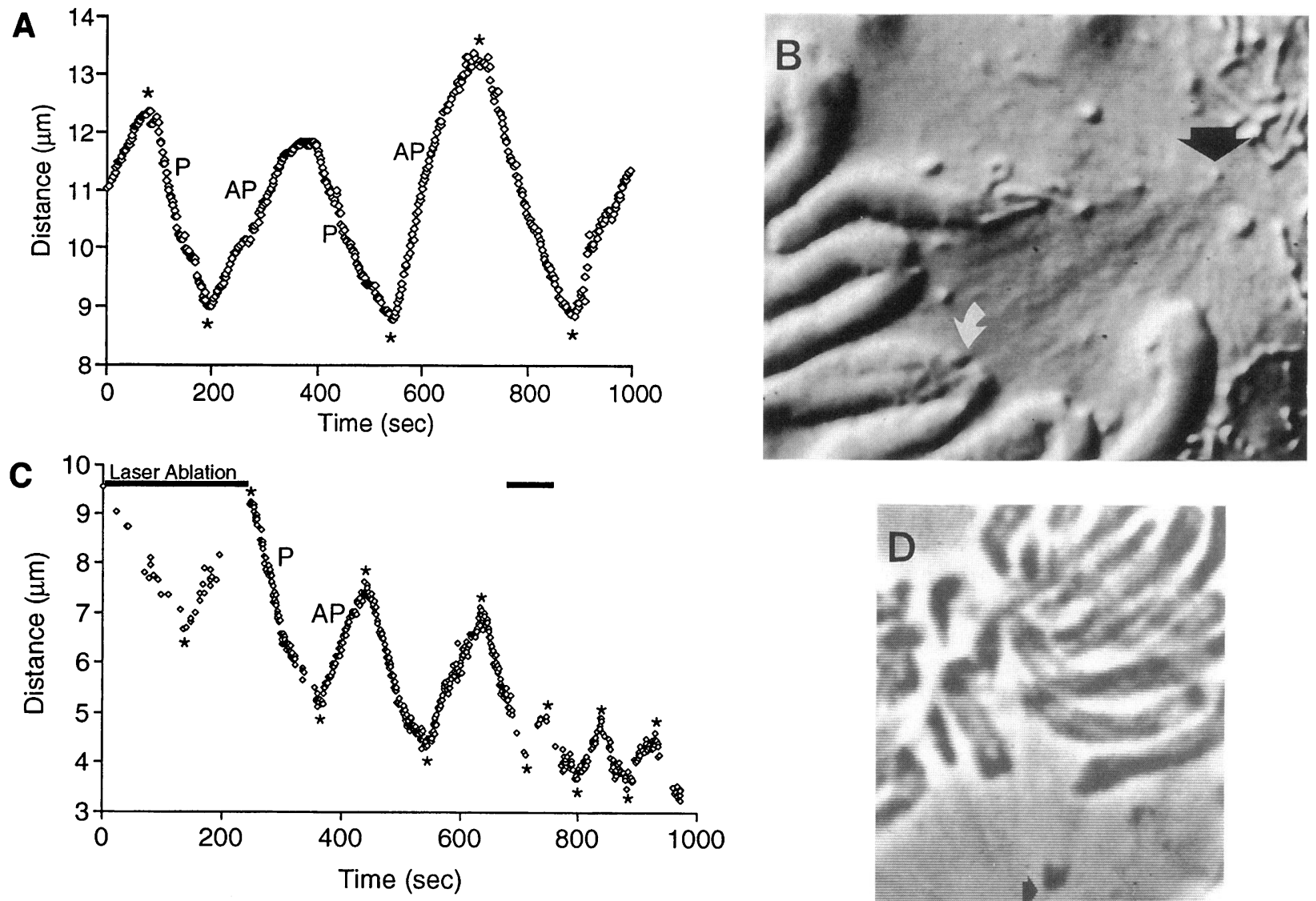

Figure 9. The velocities and abrupt switching of kinetochore motility between poleward and away from the pole movement is independent of the size of the chromosome. (A) Kinetochore directional instability for a mono-oriented chromosome (connected to only one spindle pole as in Figure 4, B and C) in a mitotic newt cell shown in panel B. (C) Kinetochore directional instability for a kinetochore on a small chromosome fragment (short black arrow in panel D, which was severed from the bulk of the chromosome arms and its sister kinetochore by laser microsurgery in the cell shown in panel D. Horizontal lines mark periods of laser surgery. The second irradiation severed the tenuous connection remaining between the centromere region and the chromosome arms. (B and D) Smaller black or white arrows show the positions of the kinetochores while the large black or clear arrows show the position of the spindle poles. Note that in the kinetic plots $(\mathrm{A})$ and $(\mathrm{C})$, the transitions $\left(^{*}\right)$ between poleward and away from the pole phases of kinetochore motility are quite abrupt. Modified from Skibbens et al. $(1993,1995)$.

tubule assembly with pure tubulin alone (Vasquez et al., 1994). So MAPs may not be the answer. Something about the structure of the attachment site could limit diffusion, restricting tubulin access to or escape from a deeply embedded microtubule tip. In addition, an obvious possibility is that the growth and shortening rates of the microtubules at the kinetochores are regulated by slow $(\sim 2 \mu \mathrm{m} / \mathrm{min})$ motors that translocate along the microtubule lattice at the plus end attachment sites (models in Figure 6 and Figure 8A).

It is fairly easy to see how slow advancement of a plus end capping assembly (either model in Figure 8) could slow microtubule growth. It is harder to envision how slow minus-end directed movement of the same complex during depolymerization can slow tu- bulin dissociation without detachment of the complex from the end. In the lateral attachment model in Figure $8 \mathrm{~A}$, the tip attachment complex could slow depolymerization without detachment if only subunits distal to the attachment sites are capable of dissociation. In the distal tip attachment model in Figure $8 \mathrm{~B}$, the binding of the attachment molecules could stabilize lateral interactions between adjacent tubulin dimers, slowing dissociation.

By whatever mechanism that operates at the kinetochore, the cell seems to have chosen to use the kinetochore as a governor, to slow down and synchronize the shortening and growth of the microtubules that collectively must bring the full set of daughter chromosomes to the spindle pole. 
Another puzzle is what does the kinetochore sense within the spindle to control its direction of movement during prometaphase congression and anaphase segregation of the chromosomes? There is evidence that motor activity can destabilize the ends of microtubules (Endow et al., 1994; Lombillo et al., 1995a). Also, combinations of plus and minus motors have been shown to generate directional instability in microtubule gliding in in vitro motility assays (Vale et al., 1993). Thus, an interesting possibility is that a combination of plus and minus motors at kinetochores may function not only as a mechanism for attachment to dynamic plus ends (Skibbens et al., 1993; Lombillo et al., 1995a), but also to synchronously switch kinetochore microtubules between growth and shortening phases of dynamic instability.

There is a long history of experimental evidence indicating that tension at the kinetochore controls the direction of motility during chromosome congression and segregation; low tension promotes switching to poleward movement or shortening of kinetochore microtubules and high tension promotes switching to movement away from the pole or growth of kinetochore microtubules (Inoué, 1952; Rieder and Salmon, 1994; Skibbens et al., 1995). But the molecular pathways between changes in kinetochore tension and changes in the direction of kinetochore motility are still unknown. Micromanipulation studies by Nicklas and Ward (1994) have also shown that tension stabilizes kinetochore microtubule attachment.

There is evidence that the onset of anaphase depends on microtubule dynamics at the kinetochore. In many cell types, anaphase onset is delayed until all chromosomes have become attached to opposite poles by kinetochore microtubules (Rieder et al., 1994). Anaphase onset is delayed by disruption of microtubule attachment to kinetochores by drugs like nocodozole and taxol, which inhibit or stabilize microtubule assembly respectively (Jordan et al., 1992; Wendell et al., 1993; Rieder et al., 1994), by detachment produced by chromosome micromanipulation (Nicklas et al., 1995), and by antibodies to centromere proteins like CENPC (Tomkiel et al., 1994). Genetic analysis in yeast systems (Murray, 1994, 1995) has identified genes (MAD1MAD3 and BUB1-BUB3) whose products are required for the anaphase onset checkpoint that detects defective spindle assembly. It will be interesting to know how these proteins interact with the kinetochore.

Very recently, intriguing light has been shed on the role that mechanical tension, acting on the kinetochores and their microtubules, appears to serve as the "checkpoint" for the cell's entry into anaphase as proposed by Hartwell and Weinert (1989) (see also McIntosh, 1991). When chromosomes become attached to opposite spindle poles by kinetochore microtubules, a net tension develops across the centromere, even for the oscillating kinetochores in vertebrate cells
(Skibbens et al., 1994). Through ingenious experiments using mantid spermatocytes, $\mathrm{Li}$ and Nicklas (1995) demonstrated that a lack of tension on the kinetochore of one of the two $X$ chromosomes, which had failed to pair with the $\mathrm{Y}$ chromosome, prevents the mitotic cell from completing metaphase, thus being arrested without being able to enter anaphase. Such a cell can, however, be made to proceed into anaphase (after a short delay) if the missing tension is applied to the stray $\mathrm{X}$ chromosome by stretching the chromosome with a microneedle. Thus the lack of tension on a kinetochore can somehow signal that an error of meiosis has been detected and eventually lead to degeneration of the cell.

A phosphorylated kinetochore epitope recognized by 3 F3 antibody appears involved with this tensiondependent signal pathway. Gorbsky and Ricketts (1993) initially discovered that in PtK1 tissue culture cells, unattached kinetochores stain brightly with the 3F3 antibody, but attached kinetochores on chromosomes near the metaphase plate and in anaphase stain dimly. Nicklas et al. (1995) have reported a similar staining pattern for kinetochores in grasshopper meiosis-I spermatocytes and gone on to provide evidence by micromanipulation experiments that it is tension, and not simply the attachment of kinetochore microtubules, which reversibly turns staining from bright to dim! In this regard, it is worth calling attention to "Teinochemical Systems" where mechanical stretching of an amphoteric gel strand changes its chemical affinity, for example, to charged ions (Kuhn et al., 1960).

\section{CONCLUDING REMARKS}

It is clear from the above survey that depolymerizing, or disassembling, microtubules can generate a pulling, or "contractile" force, and that polymerizing, or assembling, microtubules can generate a pushing, or extensive, force. These forces are of sufficient magnitude and with appropriate directionality to bipartition chromosomes in mitosis as well as position centrosomes and other organelles that are involved in the establishment of cell polarity and differentiation, albeit through the transient establishment of highly dynamic architectures in which the component subunits are rapidly turning over within the functional edifice in the living cells.

Several questions that need answering are as follows. What are the maximum forces that can be generated by individual microtubule assembly/disassembly, and how does the force depend on velocity of elongation or shortening? Is the energy stored by hydrolysis of GTP during assembly of the microtubule essential for the contractile force production? Or, does the thermodynamics of the assembly system provide adequate energy? What fraction of force generation in 
mitosis and related motility is based on assembly/ disassembly of microtubules as opposed to the sliding of microtubules or organelles powered by motor proteins such as dynein or kinesin?

What is the nature of the forces that hold the microtubule "tip" to the kinetochore, organelle or membrane, while still permitting the subunits of microtubules to enter or escape from this extending or contracting site? Is there a labile glue or wetting agent that intervenes between the microtubule tip and the attachment site? Are modified motor proteins involved in these dynamic attachments? Or, can nonmotor tubulin or microtubule-binding proteins attach at the contacting site? An interesting suggestion made by Andrew Murray (personal communication) is that "motors initially arose as nonhydrolytic components of rachet mechanisms and only later in evolution learned how to use ATP hydrolysis to walk along lateral surfaces."

What of the minus ends of the microtubules at the spindle pole? What is the nature of their anchorage, or ability not to be drawn in toward the kinetochore? As at the kinetochore, the minus end attachment site must also be dynamic because kinetochore microtubules flux toward the spindle poles in vertebrate tissue cells (Figure 4) and nonkinetochore microtubule flux has been measured in embryonic Xenopus spindles (Sawin and Mitchison, 1994). We are only beginning to understand the nature of minus end complexes and their role in force generation for chromosome movement and spindle morphogenesis.

What controls catastrophe and rescue at the kinetochore to generate synchronous behavior of the many microtubules attached to a single kinetochore during poleward and away from the pole motility? How does tension affect catastrophe and rescue? Do catastrophe and rescue take place stocastically, or are there local regulators? What are the molecular mechanisms at the kinetochore that sense tension to control the direction of kinetochore motility and anaphase onset? How does the dynamic instability of microtubules participate in moving or positioning organelles, including the centrosomes, other than chromosomes?

Many of these questions will no doubt be answered by further biochemical studies and amino acid sequence analyses, as well as through ingeniously contrived experiments on cell-free systems directly being observed, perhaps with the aid of electronically enhanced light microscopy.

At the same time we hope that the applicability of the models and paradigms emerging from in vitro experiments will be tested directly in living cells. Microtubule and organellar behavior should be closely observed at high resolution in several cell types undergoing mitosis or meiosis that can be proven to be normal, as well as in cells that are experimentally manipulated in highly localized regions, such as might be achieved by activating appropriate caged compounds with a microbeam of light, and/or with reagents with a high degree of target specificity, including altered genes. In addition to experimenting with cell types that are widely used by investigators, we should remember that nature sometimes reveals her most well kept secrets through exaggerated displays found only in exotic cell types.

After all, through extensive trial and error, nature has chosen an intricately interacting, dynamic system to achieve mitosis, and to safeguard the propagation and unfolding of life despite its myriad forms. While we are becoming privy to some of nature's surprising ways today, we need, in addition to dissecting the molecules further, to listen ever more carefully to the living cell, and be prepared to be taught further unexpected paradigms, which will undoubtedly be essential for clearer understanding of the physico-chemical and biological basis of cellular organization, life, and disease.

\section{ACKNOWLEDGMENTS}

We are grateful to Andrew Murray, Bruce Nicklas, Tim Mitchison, and Conly Rieder for their comments and criticisms of early versions of this essay. Supported by National Institutes of Health grants GM-24364 to E.D.S. and GM-316617 to S.I.

\section{REFERENCES}

Afshar, K., Barton, N.R., Hawley, R.S., and Goldstein, L.S.B. (1995). DNA binding and meiotic chromosomal localization of the Drosophila Nod kinesin-like protein. Cell 81, 129-138.

Allan, V.J., and Vale, R.D. (1991). Cell cycle control of microtubulebased transport and tubule formation in vitro. J. Cell Biol. 113, 347-359.

Allan, V.J., and Vale, R.D. (1994). Movement of membrane tubules along microtubules in vitro: evidence for specialized sites of motor attachment. J. Cell Sci. 107, 1885-1897.

Ault, J.G., and Rieder, C.L. (1994). Centrosome and kinetochore movement during mitosis. Curr. Opin. Cell Biol. 6, 41-49.

Bajer, A.S. (1982). Functional autonomy of monopolar spindle and evidence for oscillatory movement in mitosis. J. Cell Biol. 93, 33-48.

Belmont, L.D., Hyman, A.A., Sawin, K.E., and Mitchison, T.J. (1990). Real-time visualization of cell cycle-dependent changes in microtubule dynamics in cytoplasmic extracts. Cell 62, 579-589.

Bergen, L.G., and Borisy, G.G. (1980). Head-to-tail microtubule polymerization in vitro: electron microscopic analysis of seeded assembly. J. Cell Biol. 84, 141-150.

Borisy, G.G., Marcum, J.M., Olmsted, J.B., Murphy, D.B., and Johnson, K.A. (1975). Microtubule assembly in vitro? Ann. NY Acad. Sci. 253, 107-132.

Brinkley, B.R., and Cartwright, J. (1975). Cold-labile and cold-stable microtubules in the mitotic spindle of mammalian cells. Ann. NY Acad. Sci. 253, 428-439.

Caplow, M. (1992). Microtubule dynamics. Curr. Opin. Cell Biol. 4, 58-65.

Caplow, M., Ruhlen, R.L., and Shanks, J. (1994). The free energy for hydrolysis of a microtubule-bound nucleotide triphosphate is near 
zero: all of the free energy for hydrolysis is stored in the microtubule lattice. J. Cell Biol. 127, 779-788.

Carlier, M.F. (1991). Nucleotide hydrolysis in cytoskeletal assembly. Curr. Opin. Cell Biol. 3, 12-17.

Cassimeris, L., Inoué, S., and Salmon, E.D. (1988a). Microtubule dynamics in the chromosomal spindle fiber: analysis by fluorescence and high-resolution polarization microscopy. Cell Motil. Cytoskeleton 10, 185-196.

Cassimeris, L., Pryer, N.K., and Salmon, E.D. (1988b). Real-time observations of microtubule dynamic instability in living cells. J. Cell Biol. 107, 2223-2231.

Cassimeris, L., Rieder, C.L., Rupp, G., and Salmon, E.D. (1990). Stability of microtubule attachment to metaphase kinetochores in PtK $_{1}$ cells. J. Cell Sci. 96, 9-15.

Cassimeris, L., Rieder, C.L., and Salmon, E.D. (1994). Microtubule assembly and kinetochore directional instability in vertebrate monopolar spindles: implications for the mechanism of chromosome congression. J. Cell Sci. 107, 285-297.

Cassimeris, L., and Salmon, E.D. (1991). Kinetochore microtubules shorten by loss of subunits at the kinetochores of prometaphase chromosomes. J. Cell Sci. 98, 151-158.

Centonze, V.E., and Borisy, G.G. (1991). Pole-to-chromosome movements induced at metaphase: sites of microtubule disassembly. J. Cell Sci. 100, 205-211.

Chandra, R., Endow, S.A., Skeen, V., and Salmon, E.D. (1993). An $\mathrm{N}$-terminal truncation of the ncd motor protein supports diffusional movement of microtubules in motility assays. J. Cell Sci. 104, 899906.

Chrétien, D., Fuller, S.D., and Karsenti, E. (1995). Structure of growing microtubule ends: two dimensional sheets close into tubule at variable rates. J. Cell Biol. 129, 1311-1328.

Cortese, J.D., Schwab, B., Friden, C., and Elson, E.L. (1989). Actin polymerization induces a shape change in actin-containing vesicles. Proc. Natl. Acad. Sci. USA 86, 5773-5777.

Coue, M., Lombillo, V.A., and McIntosh, J.R. (1991). Microtubule depolymerization promotes particle and chromosome movement in vitro. J. Cell Biol. 112, 1165-1175.

Desai, A., and Mitchison, T.J. (1995). A new role for motor proteins as couplers to depolymerizing microtubules. J. Cell Biol. 128, 1-4.

Dreschel, D.N., Hyman, A.A., Cobb, M.H., and Kirschner, M.W. (1992). Modulation of the dynamic instability of tubulin assembly by the microtubule-associated protein tau. Mol. Biol. Cell 3, 11411154

Drechsel, D.N., and Kirschner, M.W. (1994). The minimum GTP cap required to stabilize microtubules. Curr. Biol. 4, 1053-1061.

Dye, R.B., Flicker, P.F., Lien, D.Y., and Williams, R.C., Jr. (1992). End-stabilized microtubules observed in vitro: stability, subunit interchange, and breakage. Cell Motil. Cytoskeleton 21, 171-186.

Earnshaw, W.C. (1994). Structure and molecular biology of the kinetochore. In: Microtubules, ed. J. Hyams and C. Loyyd, New York: Wiley-Liss, 393-412.

Endow, S.A., Kang, S.J., Satterwhite, L.L., Rose, M.D., Skeen, V.P., and Salmon, E.D. (1994). Yeast kar3 is a minus-end microtubule motor protein that destabilizes microtubules preferentially at the minus ends. EMBO J. 13, 2708-2713.

Erickson, H. (1974). Assembly of microtubules from preformed, ring-shaped protofilaments and 6-S tubulin. J. Supramol. Struct. 2, 393-411.

Erickson, H.P., and O'Brien, E.T. (1992). Microtubule dynamic instability and GTP hydrolysis. Annu. Rev. Biophys. Biomol. Struct. $21,145-166$.
Forer, A. (1965). Local reduction of spindle fiber birefringence in living nephrotoma suturalis spermatocytes induced by ultraviolet irradiation. J. Cell Biol. 25, 95-117.

Forer, A. (1966). Characterization of the mitotic traction system and evidence that birefringent spindle fibers neither produce nor transmit force for chromosome movement. Chromosoma 19, 44-98.

Fuller, M.T. (1995). Riding the polar winds: chromosomes motor down east. Cell $81,5-8$.

Fygenson, D.K. (1995). Microtubules: the rhythm of assembly and the evolution of form. Ph.D. Thesis, Princeton, NJ: Princeton University.

Gelfand, V.I., and Bershadsky, A.D. (1991). Microtubule dynamics: mechanism, regulation, and function. Annu. Rev. Cell Biol. 7, 93116.

Gibbons, I.R., and Rowe, A.J. (1965). Dynein: a protein with adenosine triphosphate activity from cilia. Science 149, 424-426.

Gliksman, N.R., Parsons, S.F., and Salmon, E.D. (1992). Okadaic acid induces interphase to mitotic-like microtubule dynamic instability by inactivating rescue. J. Cell Biol. 119, 1271-1276.

Gliksman, N.R., and Salmon, E.D. (1993). Microtubule-associated motility in cytoplasmic extracts of sea urchin eggs. Cell Motil. Cytoskeleton 24, 167-178.

Gliksman, N.R., Skibbens, R.V., and Salmon, E.D. (1993). How the transition frequencies of microtubule dynamic instability (nucleation, catastrophe, and rescue) regulate microtubule dynamics in interphase and mitosis: analysis using a Monte Carlo computer simulation. Mol. Biol. Cell 4, 1035-1050.

Goldstein, L.S. (1993). With apologies to Scheherazade: tails of 1001 kinesin motors. Annu. Rev. Gen. 27, 319-351.

Goodson, H.V., Kang, S.J., and Endow, S.A. (1994). Molecular phylogeny of the kinesin family of microtubule motor proteins. J. Cell Sci. 107, 1875-1884.

Gorbsky, G.H., Sammak, P.J., and Borisy, G.G. (1987). Chromosomes move poleward in anaphase along stationary microtubules that coordinately disassemble from their kinetochores ends. J. Cell Biol. 104, 9-18.

Gorbsky, G.J., Sammak, P.J., and Borisy, G.G. (1988). Microtubule dynamics and chromosome motion visualized in living anaphase cells. J. Cell Biol. 106, 1185-1192.

Gorbsky, G.J., and Ricketts, W.A. (1993). Differential expression of a phosphoepitope at the kinetochores of moving chromosomes. J. Cell Biol. 122, 1311-1321.

Harris, P. (1962). Some structural and functional aspects of the mitotic apparatus in sea urchin embryos. J. Cell Biol. 14, 475-485.

Hartwell, L.H., and Weinert, T.A. (1989). Checkpoints: controls that ensure the order of cell cycle events. Science 246, 629-634.

Hayden, J.H., Bowser, S.S., and Rieder, C.L. (1990). Kinetochores capture astral microtubules during chromosome attachment to the mitotic spindle: direct visualization in live newt lung cells. J. Cell Biol. 111, 1039-1045.

Heidemann, S.R., and McIntosh, J.R. (1980). Visualization of the structural polarity of microtubules. Nature 286, 517-519.

Hill, T., and Kirschner, M. (1982). Bioenergetics and kinetics of microtubule and actin filament assembly and disassembly. Int. Rev. Cytol. 78, 1-125.

Hill, T.L. (1985). Theoretical problems related to the attachment of microtubules to kinetochores. Proc. Natl. Acad. Sci. USA 82, 44044408 . 
Horio, T., and Hotani, H. (1986). Visualization of the dynamic instability of individual microtubules by darkfield microscopy. Nature 321, 605-607.

Hotani, H., and Miyamoto, H. (1990). Dynamic features of microtubules as visualized by dark-field microscopy. Adv. Biophys. 26, 135-156.

Howard, W.D., and Timasheff, S.N. (1986). GDP state of tubulin: stabilization of double rings. Biochemisty 25, 8292-8300.

Hoyt, M.A. (1994). Cellular roles of kinesin and related proteins. Curr. Opin. Cell Biol. 6, 63-68.

Hunt, A.J., Gittes, F., and Howard, J. (1994). The force exerted by a single kinesin molecule against a viscous load. Biophys. J. 67, 766781 .

Hyman, A.A., Chrétien, D., Arnal, I., and Wade, R.H. (1995). Structural changes accompanying GTP hydrolysis in microtubules: information from a slowly hydrolyzable analogue guanylyl-(a,b)-methylene-diphosphate. J. Cell Biol. 128, 117-125.

Hyman, A.A., Middleton, K., Centola, M., Mitchison, T.J., and Carbon, J. (1992a). Microtubule-motor activity of a yeast centromerebinding protein complex. Nature 359, 533-536.

Hyman, A.A., and Mitchison, T.J. (1991). Two different microtubulebased motor activities with opposite polarities in kinetochores. Nature 351, 206-211.

Hyman, A.A., Salser, S., Drechsel, D., Unwin, N., and Mitchison, T.J. (1992b). Role of GTP hydrolysis in microtubule dynamics: information from a slowly hydrolyzable analogue, GMPCPP. Mol. Biol. Cell 3, 1155-1167.

Inoué, S. (1951). Ph.D Thesis. Studies of the structure of the mitotic spindle in living cells with an improved polarization microscope. Princeton, NJ: Princeton University.

Inoué, $\mathrm{S}$. (1952). The effect of colchicine on the microscopic and sub-microscopic structure of the mitotic spindle. Exp. Cell Res. Suppl. 2, 305-312.

Inoué, S. (1953). Polarization optical studies of the mitotic spindle. I. The demonstration of the spindle fibers in living cells. Chromosoma 5, 199-208.

Inoué, S. (1959). Motility of cilia and the mechanism of mitosis. Rev. Mod. Phys. 31, 402-408.

Inoué, S. (1960). On the physical properties of the mitotic spindle. Ann. NY Acad. Sci. 90, 529-530.

Inoué, S. (1964). Organization and function of the mitotic spindle. In: Primitive Motile Systems in Cell Biology, ed. R.D. Allen and N. Kamiya, New York: Academic Press, 549-598.

Inoué, S. (1981). Cell division and the mitotic spindle. J. Cell Biol.91, 131-147.

Inoué, S. (1990). Dynamics of mitosis and cleavage. Ann. NY Acad. Sci. 582, 1-14.

Inoué, S., Fuseler, J., Salmon, E.D., and Ellis, G.W. (1975). Functional organization of mitotic microtubules: physical chemistry of the in vivo equilibrium system. Biophys. J. 15, 725-744.

Inoué, S., and Sato, H. (1967). Cell motility by labile association of molecules: the nature of mitotic spindle fibers and their role in chromosome movement. J. Gen. Physiol. 50, 259-292.

Janmey, P., Cunningham, C., Oster, G., and Stossel, T. (1992). Cytoskeletal networks and osmotic pressure in relation to cell structure and motility. In: Swelling Mechanics: From Clays to Living Cells and Tissues, ed. T. Karalis, Heidelberg: Springer Verlag.

Jordan, M.A., Thrower, D., and Wilson, L. (1992). Effects of vinblastine, podophyllotoxin and nocodazole on mitotic spindles. J. Cell Sci. 102, 401-416.
Kirschner, M., Honig, L., and Williams, R. (1975). Quantitative electron microscopy of microtubule assembly in vitro. J. Mol. Biol. 99, 263-276.

Kirschner, M., Williams, R., Weingarten, M., and Gerhart, J. (1974). Microtubules from mammalian brain: some properties of their depolymerization products and a proposed mechanism of assembly and disassembly. Proc. Natl. Acad. Sci. USA 71, 1159-1163.

Koshland, D.E., Mitchison, T.J., and Kirschner, M.W. (1988). Polewards chromosome movement driven by microtubule depolymerization in vitro. Nature 331, 499-504.

Kuhn, W., Ramel, A., Walters, D.H., Ebner, G., and Kuhn, H.J. (1960). The production of mechanical energy from different forms of chemical energy with homogeneous and cross-striated high polymer systems. Fortschr. Hochpolym.-Forsch. 1, 540-592.

Kuo, S.C., and Sheetz, M.P. (1993). Force of single molecules measured with optical tweezers. Science 260, 232-234.

Leslie, R.J. (1992). Chromosomes attain a metaphase postion on half-spindles in the absence of an opposing spindle pole. J. Cell Sci. 103, 125-130.

Li, X., and Nicklas, R.B. (1995). Mitotic forces control a cell-cycle checkpoint. Nature 373, 630-632.

Lombillo, V.A., Stewart, R.J., and McIntosh, J.R. (1995a). Kinesin supports minus end-directed, depolymerization-driven motility of microspheres coupled to shortening microtubules. Nature $373,161-$ 164.

Lombillo, V.A., Nislow, C., Yen, T.J., Gelfand, V.I., and McIntosh, J.R. (1995b). Antibodies to the kinesin motor domain and CENP-E inhibit microtubule depolymerization-dependent motion of chromosomes in vitro. J. Cell Biol. 128, 107-115.

Mandelkow, E.-M., and Mandeldow, E. (1992). Microtubule oscillations. Cell Motil. Cytoskeleton 22, 235-244.

Mandelkow, E.-M., Mandelkow, E., and Milligan, R.A. (1991). Microtubule dynamics and microtubule caps: a time-resolved cryoelectron microscopy study. J. Cell Biol. 114, 977-991.

Mandelkow, E.M., Schultheiss, R., Rapp, R., Muller, M., and Mandelkow, E. (1986). On the surface lattice of microtubules: helix starts, protofilament number, seam, and handedness. J. Cell Biol. 102, 1067-1073.

Margolis, R.L., and Wilson, L. (1978). Opposite end assembly and disassembly of microtubules at steady state in vitro. Cell 13, 1-8.

McDonald, H.B., Stewart, R.J., and Goldstein, L.S.B. (1990). The kinesin-like $n c d$ protein of Drosophila is a minus end-directed microtubule motor. Cell 63, 1159-1165.

McDonald, K.L., O'Toole, E.T., Mastronarde, D.N., and McIntosh, J.R. (1992). Kinetochore microtubules in PTK cells. J. Cell Biol. 118, 369-383.

McIntosh, J.R. (1991). Structural and mechanical control of mitotic progression. Cold Spring Harbor Symp. Quant. Biol. 56, 613-619.

McIntosh, J.R. (1994). The roles of microtubules in chromosome movement. In: Microtubules, ed. J. Hyams and C. Loyyd, New York: Wiley-Liss, 413-434.

McIntosh, J.R., and Euteneuer, U. (1984). Tubulin hooks as probes of microtubule polarity: an analysis of the method and an evaluation of data on microtubule polarity in the mitotic spindle. J. Cell Biol. 98, 525-533.

McIntosh, J.R., Hepler, P.K., and Van Wie, D.G. (1969). Model for mitosis. Nature 224, 659-663.

McIntosh, J.R., and Koonce, M.P. (1989). Mitosis. Science 246, 622628. 
McIntosh, J.R., and Pfarr, C.M. (1991). Mitotic motors. J. Cell Biol. 115, 577-585.

Melki, R., Carlier, M.-F., Pantaloni, D., and Timasheff, S.N. (1989). Cold depolymerization of microtubules to double rings: geometric stabilization of assemblies. Biochemistry 28, 9143-9152.

Merdes, A., and De Mey, J. (1990). The mechanism of kinetochorespindle attachment and polewards movement analyzed in $\mathrm{PtK}_{2}$ cells at the prophase-prometaphase transition. Eur. J. Cell Biol. 53, 313325 .

Middleton, K., and Carbon, J. (1994). KAR3-encoded kinesin is a minus end-directed motor that functions with centromere binding proteins (CBF3) on an in vitro yeast kinetochore. Proc. Natl. Acad. Sci. USA 91, 7212-7216.

Mitchison, T.J. (1988). Microtubule dynamics and kinetochore function in mitosis. Annu. Rev. Cell Biol. 4, 527-549.

Mitchison, T.J. (1989). Polewards microtubule flux in the mitotic spindle: evidence from photoactivation of fluorescence. J. Cell Biol. 109, 637-652.

Mitchison, T.J. (1993). Localization of an exchangeable GTP binding site at the plus end of microtubules. Science 261, 1044-1047.

Mitchison, T., and Kirschner, M. (1984a). Dynamic instability of microtubule growth. Nature 312, 237-242.

Mitchison, T., and Kirschner, M. (1984b). Microtubule assembly nucleated by isolated centrosomes. Nature 312, 232-237.

Mitchison, T.J., Evans, L., Schulze, E., and Kirschner, M. (1986). Sites of microtubule assembly and disassembly in the mitotic spindle. Cell 45, 515-527.

Mitchison, T.J., and Salmon, E.D. (1992). Poleward kinetochore fiber movement occurs during both metaphase and anaphase-A in newt lung cell mitosis. J. Cell Biol. 119, 569-582.

Miyamoto, H., and Hotani, H. (1988). Polymerization of microtubules in liposomes produces morphological changes of shape. Proc. Tanaguchi Internat. Symp. 14, 220-242.

Miyata, H., and Hotani, H. (1992). Morphological changes in liposomes caused by polymerization of encapsulated actin and spontaneous formation of actin bundles. Proc. Natl. Acad. Sci. USA 89, 11547-11551.

Murphy, T.D., and Karpen, G.H. (1995). Interactions between the nod + kinesin-like gene and extracentromeric sequences are required for transmission of a Drosophila minichromosome. Cell 81 139-148.

Murray, A.W. (1994). Cell cycle checkpoints. Curr. Opin. Cell Biol. 6 , 872-876.

Murray, A.W. (1995). Genetics of cell cycle checkpoints. Curr. Opin. Genet. Dev. 5, (in press).

Murray, A.W., and Mitchison, T.J. (1994). Kinetochores pass the IQ test. Curr. Biol. 4, 38-41.

Nicklas, R.B. (1988). The forces that move chromosomes in mitosis. Ann. Rev. Biophys. Biophys. Chem. 17, 431-449.

Nicklas, R.B., and Ward, S.C. (1994). Elements of error correction in mitosis: microtubule capture, release, and tension. J. Cell Biol. 126, 1241-1253.

Nicklas, R.B., Ward, S.C., and Gorbsky, G.J. (1995). Kinetochore chemistry is sensitive to tension and may link mitotic forces to a cell cycle checkpoints. J. Cell Biol. 130, 929-939.

Oakley, B.R. (1992). Gamma-tubulin: the microtubule organizer? Trends Cell Biol. 2, 1-5.

Olmsted, J.B., and Borisy, G.G. (1975). Ionic and nucleotide requirements for microtubule polymerization in vitro. Biochemistry 14 , 2996-3005.
Ookata, K., Hisanaga, S., Bulinski, J.C., Murofushi, H., Aizawa, H., Itoh, T.J., Hotani, H., Okumura, E., Tachibana, K., and Kishimoto, T. (1995). Cyclin B interaction with microtubule-associated protein 4 (MAP4) targets p34 ${ }^{\text {cdc2 }}$ kinase to microtubules and is a potential regulator of M-phase microtubule dynamics. J. Cell Biol. 128, 849862 .

Östergren, G. (1949). Luzula and the mechanism of chromosome movement. Hereditas 35, 525-528.

Peskin, C.S., Odell, G.M., and Oster, G.F. (1993). Cellular motions and thermal fluctuations: the Brownian ratchet. Biophys. J. 65, 316324.

Pfarr, C.M., Coue, M., Grissom, P.M., Hays, T.S., Porter, M.E., and McIntosh, J.R. (1990). Cytoplasmic dynein is localized to kinetochores during mitosis. Nature 345, 263-265.

Pierre, P., Scheel, J., Rickard, J.E., and Kreis, T.E. (1992). CLIP 170 links endocytic vesicles to microtubules. Cell 70, 887-900.

Porter, K.R. (1966). Cytoplasmic microtubules and their functions. In: Ciba Foundation Symposium, Principles Biomolecular Organization, ed. G.E.W. Wolstenholme and M. O'Connor, London, 308356.

Pryer, N.K., Walker, R.A., Skeen, V.P., Bourns, B.D., Soboerio, M.F., and Salmon, E.D. (1992). Brain microtubule-associated proteins modulate microtubule dynamic instability in vitro: real-time observations using video microscopy. J. Cell Sci. 103, 965-976.

Rayment, I. (1993). Structure of the actin-myosin complex and its implication for muscle contraction. Science 261, 58-65.

Rayment, I., Rypniewski, W.R., Schmidt-Bäse, K., Smith, R., Tomchick, D.R., Benning, M.M., Winkelmann, D.A., Wesenberg, G., and Holden, H.M. (1993). Three-dimensional structure of myosin subfragment-1: a molecular motor. Science 261, 50-65.

Rieder, C.L. (1981). The structure of the cold-stable kinetochore fiber in metaphase PtK $_{1}$ cells. Chromosoma 84, 145-158.

Rieder, C.L. (1982). The formation, structure, and composition of the mammalian kinetochore and kinetochore fiber. Int. Rev. Cytol. 79, $1-58$.

Rieder, C.L., Alexander, S.P., and Rupp, G. (1990). Kinetochores are transported poleward along a single astral microtubule during chromosome attachment to the spindle in newt lung cells. J. Cell Biol. 110, 81-95.

Rieder, C.L., Davison, E.A., Jensen, L.C.W., Cassimeris, L., and Salmon, E.D. (1986). Oscillatory movements of mono-oriented chromosomes and their position relative to the spindle pole result from the ejection properties of the aster and half-spindle. J. Cell Biol. 103, 581-591.

Rieder, C.L., and Salmon, E.D. (1994). Motile kinetochores and polar ejection forces dictate chromosome position on the vertebrate mitotic spindle. J. Cell Biol. 124, 223-233.

Rieder, C.L., Schultz, A., Cole, R., and Sluder, G. (1994). Anaphase onset in vertebrate somatic cells is controlled by a checkpoint that monitors sister kinetochore attachment to the spindle. J. Cell Biol. $127,1301-1310$

Salmon, E.D. (1975). Pressure-induced depolymerization of brain microtubules in vitro. Science $189,884-886$.

Salmon, E.D. (1976). Pressure-induced depolymerization of spindle microtubules. IV. Production and regulation of chromosome movement. In: Cell Motility. Cold Spring Harbor Conferences of Cell Proliferation, vol. 3, ed. R. Goldman, T. Pollard, and J. Rosenbaum, Cold Spring Harbor, NY: Cold Spring Harbor Laboratory Press, 1329-1342.

Salmon, E.D. (1988). A model of metaphase chromosome congression and anaphase poleward movement. In: Cell Movement: Kinesin and Microtubule-Associated Proteins, ed. F.D. Warner and J.R. McIntosh, New York: Alan R. Liss, 431-440. 
Salmon, E.D. (1989). Microtubule dynamics and chromosome movement. In: Mitosis: Molecules and Mechanisms, ed. J. Hyam, and B.R. Brinkley, New York: Academic Press Limited, 119-182.

Salmon, E.D., Goode, D., Maugel, T.K., and Bonar, D.B. (1976). Pressure-induced depolymerization of spindle microtubules. III. Differential stability in HeLa cells. J. Cell Biol. 69, 443-454.

Salmon, E.D., Leslie, R.J., Saxton, W.M., Karow, M.L., and McIntosh, J.R. (1984). Spindle microtubule dynamics in sea urchin embryos: analysis using a fluorescein-labeled tubulin and measurements of fluorescence redistribution after laser photobleaching. J. Cell Biol. 99, 2165-2174.

Sato, H., Ellis, G.W., and Inoué, S.I. (1975). Microtubular origin of mitotic spindle from birefringence: demonstration of the applicability of Weiner's equation. J. Cell Biol. 67, 501-517.

Saunders, W.S., and Hoyt, M.A. (1992). Kinesin-related proteins required for structural integrity of the mitotic spindle. Cell 70, 451-458.

Sawin, K.E., and Endow, S.A. (1993). Meiosis, mitosis and microtubule motors. BioEssays 15, 399-407.

Sawin, K.E., and Mitchison, T.J. (1994). Microtubule flux in mitosis is independent of chromosomes, centrosomes, and antiparallel microtubules. Mol. Biol. Cell 5, 217-226.

Saxton, W.M., Stemple, D.L., Leslie, R.J., Salmon, E.D., Zavortink, M., and McIntosh, J.R. (1984). Tubulin dynamics in cultured mammalian cells. J. Cell Biol. 99, 2175-2186.

Scheel, J., and Kreis, T.E. (1991). Motor protein-independent binding of endocytic carrier vesicles to microtubules in vitro. J. Biol. Chem. $266,18141-18148$.

Schrader, F. (1953). Mitosis: The Movement of Chromosomes in Cell Division, 2nd ed., Columbia University Press, New York.

Sheldon, E., and Wadsworth, P. (1992). Microinjection of biotintubulin into anaphase cells induces transient elongation of kinetochore microtubules and reversal of chromosome-to-pole motion. J. Cell Biol. 116, 1409-1420.

Shelden, E., and Wadsworth, P. (1993). Observation and quantification of individual microtubule behavior in vivo: microtubule dynamics are cell-type specific. J. Cell Biol. 120, 935-945.

Simon, J.R., Adam, N.A., and Salmon, E.D. (1991). Microtubules and tubulin sheet polymers elongate from isolated axonemes in vitro as observed by negative-stain electron microscopy. Micron Microsc. Acta. 22, 405-412.

Simon, J.R., Parsons, S.F., and Salmon, E.D. (1992). Buffer conditions and non-tubulin factors critically affect the microtubule dynamic instability of sea urchin egg tubulin. Cell Motil. Cytoskeleton 21, 1-14.

Simon, J.R., and Salmon, E.D. (1990). The structure of microtubule ends during the elongation and shortening phases of dynamic instability examined by negative-stain electron microscopy. J. Cell Sci. 96, 571-582.

Skibbens, R., Rieder, C.L., and Salmon, E.D. (1995). Kinetochore motility after severing between sister chromosomes using laser microsurgery: evidence that kinetochore directional instability and position is regulated by tension. J. Cell Sci. 108, 2537-2548.

Skibbens, R.V., Skeen, V.P., and Salmon, E.D. (1993). Directional instability of kinetochore motility during chromosome congression and segregation in mitotic newt lung cells: a push-pull mechanism. J. Cell Biol. 122, 859-875.

Skibbens, R.V., Waters, J.C., and Salmon, E.D. (1994). Oscillating vertebrate kinetochores are on average under tension. Mol. Biol. Cell 5, 410a.
Snyder, M. (1994). The spindle pole body of yeast. Chromosoma 103, 369-380.

Song, Y.-H., and Mandelkow, E. (1995). The anatomy of flagellar microtubules: polarity, seam, junctions, and lattice. J. Cell Biol. 128, 81-94.

Spurck, T.P., Stonington, O.G., Snyder, J.A., Pickett-Heaps, J.D., Bajer, A., and Mole-Bajer, J. (1990). UV microbeam irradiations of the mitotic spindle. II. Spindle fiber dynamics and force production. J. Cell Biol. 111, 1505-1518.

Steuer, E.R., Wordeman, L., Schroer, T.A., and Sheetz, M.P. (1990). Localization of cytoplasmic dynein to mitotic spindles and kinetochores. Nature 345, 266-268.

Stewart, R.J., Farrell, K.W., and Wilson, L. (1990). Role of GTP hydrolysis in microtubule polymerization: evidence for a coupled hydrolysis mechanism. Biochemistry 29, 6489-6498.

Stewart, R.J., Thaler, J.P., and Goldstein, L.S.B. (1993). Direction of microtubule movement is an intrinsic property of the motor domains of kinesin heavy chain and Drosophila ncd protein. Proc. Natl. Acad. Sci. USA 90, 5209-5213.

Svoboda, K., and Block, S.M. (1994). Force and velocity measured for single kinesin molecules. Cell 77, 773-784.

Telzer, B.R., and Haimo, L.T. (1981). Decoration of spindle microtubules with dynein: evidence for uniform polarity. J. Cell Biol. 89, 373-378.

Theurkauf, W.E., and Hawley, R.S. (1992). Meiotic spindle assembly in Drosophila females: behavior of nonexchange chromosomes and the effects of mutations in the nod kinesin-like protein. J. Cell Biol. $116,1167-1180$.

Tomkiel, J., Cooke, C.A., Saitoh, H., Bernat, R.L., and Earnshaw, W.C. (1994). CENP-C is required for maintaining proper kinetochore size and for a timely transition to anaphase. J. Cell Biol. 125, 531-545.

Vale, R.D., Malik, F., and Brown, D. (1993). Directional instability of microtubule transport in the presence of kinesin and dynein, two opposite polarity motor proteins. J. Cell Biol. 119, 1589-1596.

Vale, R.D., Soll, D.R., and Gibbons, I.R. (1989). One-dimensional diffusion of microtubules bound to flagellar dynein. Cell 59, 915925.

Vallee, R. (1993). Molecular analysis of the microtubule motor dynein. Proc. Natl. Acad. Sci. USA 90, 8769-8772.

Vasquez, R.J., Gard, D.L., and Cassimeris, L. (1994). XMAP from Xenopus eggs promotes rapid plus end assembly of microtubules and rapid microtubule polymer turnover. J. Cell Biol. 127, 985-993.

Verde, F., Dogterom, M., Stelzer, E., Karsenti, E., and Leibler, S. (1992). Control of microtubule dynamics and length by cyclin Aand cyclin B-dependent kinases in Xenopus egg extracts. J. Cell Biol. $118,1097-1108$.

Vernos, I., Raats, J., Hirano, T., Heasman, J., Karsenti, E., and Wylie, C. (1995). Xklp1, a chromosomal Xenopus kinesin-like protein essential for spindle organization and chromosome positioning. Cell 81, 117-127.

Voter, W.A., and Erickson, H.P. (1991). Dilution-induced disassembly of microtubules: relation to dynamic instability and the GTP cap. Cell Motil. 18, 55-62.

Wadsworth, P. (1993). Mitosis: spindle assembly and chromosome motion. Curr. Opin. Cell Biol. 5, 123-128.

Wadsworth, P., and Salmon, E.D. (1986). Analysis of the treadmilling model during metaphase of mitosis using fluorescence recovery after photobleaching. J. Cell Biol. 102, 1032-1038. 
Wadsworth, P., Shelden, E., Rupp, G., and Rieder, C.L. (1989). Biotin-tubulin incorporates into kinetochore fiber microtubules during early but not late anaphase. J. Cell Biol. 109, 2257-2265.

Walker, R.A., Inoué, S., and Salmon, E.D. (1989). Asymmetric behavior of severed microtubule ends after ultraviolet-microbeam irradiation of individual microtubules in vitro. J. Cell Biol. 108, 931-937.

Walker, R.A., O'Brien, E.T., Pryer, N.K., Soboeiro, M.F., Voter, W.A., Erickson, H.P., and Salmon, E.D. (1988). Dynamic instability of individual microtubules analyzed by video light microscopy: rate constants and transition frequencies. J. Cell Biol. 107, 1437-1448.

Walker, R.A., Pryer, N.K., and Salmon, E.D. (1991). Dilution of individual microtubules observed in real time in vitro: evidence that cap size is small and independent of elongation rate. J. Cell Biol. 114, 73-81.

Walker, R.A., Salmon, E.D., and Endow, S.A. (1990). The Drosophila claret segregation protein is a minus end-directed motor molecule. Nature 347, 780-782.

Walker, R.W., and Sheetz, M.P. (1993). Cytoplasmic microtubuleassociated motors. Annu. Rev. Biochem. 62, 429-451.

Wang, S.-Z., and Adler, R. (1995). Chromokinesin: a DNA-binding, kinesin-like nuclear protein. J. Cell Biol. 128, 761-768.

Waterman-Storer, C.M., Gregory, J., Parsons, S.F., and Salmon, E.D. (1995). Membrane/microtubule tip attachment complexes (TACs) allow the assembly dynamics of plus ends to push and pull membranes into tubulovesicular networks in interphase Xenopus egg extracts. J. Cell Biol. 130, 1161-1169.
Weisenberg, R.C. (1972). Microtubule formation in vitro in solutions containing low calcium concentrations. Science 177, 1104-1105.

Wendell, K.L., Wilson, L., and Jordan, M.A. (1993). Mitotic block in HeLa cells by vinblastine: ultrastructural changes in kinetochoremicrotubule attachment and in centrosomes. J. Cell Sci. 104, 261274.

Wilson, E.B. (1928). The Cell in Development and Heredity, 3rd ed., MacMillan, New York.

Wilson, P.J., Forer, A., and Leggiadro, C. (1994). Evidence that kinetochore microtubules in crane-fly spermatocytes disassemble during anaphase primarily at the poleward end. J. Cell Sci. 107, 3015-3027.

Wise, D., Cassimeris, L., Rieder, C.L., Wadsworth, P., and Salmon, E.D. (1991). Chromosome fiber dynamics and congression oscillations in metaphase $\mathrm{PtK}_{2}$ cells at 23 degrees celsius. Cell Motil. Cytoskeleton 18, 1-12.

Wordeman, L., and Mitchison, T.J. (1995). Identification and partial characterization of mitotic centromere-associated kinesin, a kinesinrelated protein that associates with centromeres during mitosis. J. Cell Biol. 128, 95-105.

Yen, T.J., Compton, D.A., Wise, D., Zinowski, R.P., Brinkley, B.R. Earnshaw, W.C., and Cleveland, D.W. (1991). CENP-E, a novel human centromere-associated protein required for progression from metaphase to anaphase. EMBO J. 10, 1245-1254.

Yen, T.J., Li, G., Schaar, B.T., Szilak, I., and Cleveland, D.W. (1992). CENP-E is a putative kinetochore motor that accumulates just before mitosis. Nature 359, 536-539. 